\title{
Charged particle induced reaction cross section data for production of the emerging medically important positron emitter ${ }^{64} \mathrm{Cu}$ : A comprehensive evaluation
}

\author{
By M. N. Aslam ${ }^{1,2}$, S. Sudár ${ }^{2}$, M. Hussain ${ }^{1,2}$, A. A. Malik ${ }^{1}$, H. A. Shah ${ }^{1}$ and S. M. Qaim"* \\ ${ }^{1}$ Department of Physics, Government College University, Lahore 54000, Pakistan \\ 2 Institute of Experimental Physics, University of Debrecen, 4001 Debrecen, Hungary \\ ${ }^{3}$ Institut für Nuklearchemie, Forschungszentrum Jülich GmbH, 52425 Jülich, Germany
}

(Received March 5, 2009; accepted in final form June 23, 2009)

\section{${ }^{64} \mathrm{Cu} /$ Charged particle induced reaction / Cross section / Excitation function / Nuclear model calculation / Data evaluation / Integral yield}

\begin{abstract}
Summary. The radionuclide ${ }^{64} \mathrm{Cu}\left(T_{1 / 2}=12.7 \mathrm{~h}\right)$ is an important non-standard positron emitter, suitable for combining PET imaging and targeted therapy. Its production in nocarrier-added form is done via charged particle induced reactions, and considerable amount of cross section data are available in the literature. We evaluated seven reactions, namely ${ }^{64} \mathrm{Ni}(p, n){ }^{64} \mathrm{Cu},{ }^{64} \mathrm{Ni}(d, 2 n){ }^{64} \mathrm{Cu},{ }^{68} \mathrm{Zn}(p, \alpha n){ }^{64} \mathrm{Cu}$, ${ }^{66} \mathrm{Zn}(p, 2 p n){ }^{64} \mathrm{Cu}, \quad{ }^{64} \mathrm{Zn}(d, 2 p){ }^{64} \mathrm{Cu}, \quad{ }^{66} \mathrm{Zn}(d, \alpha){ }^{64} \mathrm{Cu} \quad$ and ${ }^{\text {nat }} \mathrm{Zn}(d, x){ }^{64} \mathrm{Cu}$. Data analysis was generally limited up to about $25 \mathrm{MeV}$ and the consistency check of experimental data was carried out using the nuclear model codes STAPRE, EMPIRE and TALYS. In a few cases experimental data were available up to $100 \mathrm{MeV}$; the consistency check in the high energy region was done only using the code TALYS. A statistical procedure (supported by nuclear model calculations) was then used to fit the data. The derived recommended sets of data, together with $95 \%$ confidence limits, are reported. The integral yields calculated from those data are also given. A critical comparison of the various production routes of ${ }^{64} \mathrm{Cu}$ is presented. The ${ }^{64} \mathrm{Ni}(p, n){ }^{64} \mathrm{Cu}$ reaction, utilizing a highly enriched target, is the method of choice.
\end{abstract}

\section{Introduction}

The significance of positron emission tomography (PET) in diagnostic nuclear medicine is increasing and today this non-invasive technique is routinely used in neurology, cardiology, oncology and several other areas [1]. The positron emitters used in preparing the suitable radiopharmaceuticals are of organic nature and are generally short-lived [1]. For studying slow metabolic processes, however, some longer lived positron emitters (half-life between a few hours and a few days) are needed. Their use could extend to labeling of organic compounds leading to analogue tracers (e.g. with halogens) or to preparation of metal complexes (e.g. with copper). Several important or potentially important

\footnotetext{
*Author for correspondence (E-mail: s.m.qaim@fz-juelich.de).
}

longer lived positron emitters, now termed as non-standard positron emitters, have been developed [2,3], and recently a whole workshop was devoted to their study [see special issue of the Quarterly Journal of Nuclear Medicine and Molecular Imaging 52(2), 101-206 (2008)]. In general, the major constraint on PET imaging with non-standard positron emitters is the high end-point positron energy and the emission of several $\gamma$-rays during the decay. These may cause reduction of spatial resolution and blurring of the image. However, with the development of efficient algorithms these effects could be suppressed or corrected efficiently $[4,5]$. Presently three radionuclides, namely ${ }^{64} \mathrm{Cu}\left(T_{1 / 2}=12.7 \mathrm{~h}\right)$, ${ }^{86} \mathrm{Y}\left(T_{1 / 2}=14.7 \mathrm{~h}\right)$ and ${ }^{124} \mathrm{I}\left(T_{1 / 2}=4.18 \mathrm{~d}\right)$ are finding worldwide attention. This work deals with ${ }^{64} \mathrm{Cu}$.

The radioisotopes of copper have great potential for preparing metal-chelates for medical use [6]. In particular the radionuclide ${ }^{64} \mathrm{Cu}$ is very well suited: it has appropriate half-life, a low $\beta^{+}$end-point energy of $0.65 \mathrm{MeV}$, comparable to that of ${ }^{18} \mathrm{~F}\left(T_{1 / 2}=110 \mathrm{~min}\right)$, the most commonly used positron emitter, and practically no $\gamma$-ray. These decay properties are almost ideal for imaging. The only drawback is the relatively low $\beta^{+}$abundance. On the other hand, its multiple decay mode (i.e., EC (43.8\%), $\beta^{+}(17.8 \%)$ and $\beta^{-}(38.4 \%)$ ) renders it suitable for combining PET imaging and targeted therapy [7-10]. A pre-requisite of those studies, however, is the availability of ${ }^{64} \mathrm{Cu}$ of very high purity and of very high specific activity.

In early tracer studies more than 30 years ago, ${ }^{64} \mathrm{Cu}$ was produced in a nuclear reactor via the ${ }^{63} \mathrm{Cu}(n, \gamma)^{64} \mathrm{Cu}$ reaction. With the increasing demand on the specific activity the ${ }^{64} \mathrm{Zn}(n, p){ }^{64} \mathrm{Cu}$ reaction was utilized. The cross section data for this reaction have been recently evaluated [11]. The yields are, however, low and the radionuclidic purity is often unsatisfactory (in particular ${ }^{67} \mathrm{Cu}$ is the common impurity). The use of charged particle induced reactions for production of no-carrier-added ${ }^{64} \mathrm{Cu}$ is thus absolutely necessary.

The real breakthrough in the production of ${ }^{64} \mathrm{Cu}$ of high-quality was achieved after the suggestion made by the group at the Forschungszentrum Jülich to employ the ${ }^{64} \mathrm{Ni}(p, n){ }^{64} \mathrm{Cu}$ reaction [12]. Through precise measurement of the excitation function, utilizing highly-enriched ${ }^{64} \mathrm{Ni}$ as target material, and development of an ion-exchange chro- 
matographic separation method to obtain pure no-carrieradded ${ }^{64} \mathrm{Cu}$ and to recover the enriched target material for reuse, the feasibility of the procedure was demonstrated. The method was further developed at the Washington University in St. Louis [13] and the National Institutes of Health in Bethesda [14] and today about $40 \mathrm{GBq}$ amounts of ${ }^{64} \mathrm{Cu}$ are routinely produced. Nonetheless, besides this reaction, which has now become the method of choice, six other proton and deuteron induced reactions on nickel and zinc have also been investigated (for a brief overview cf. [15]).

In this work the cross section data for all seven investigated nuclear reactions, viz. ${ }^{64} \mathrm{Ni}(p, n){ }^{64} \mathrm{Cu},{ }^{64} \mathrm{Ni}(d, 2 n){ }^{64} \mathrm{Cu}$, $\left.{ }^{68} \mathrm{Zn}(p, \alpha n)\right)^{64} \mathrm{Cu}, \quad{ }^{66} \mathrm{Zn}(p, 2 p n){ }^{64} \mathrm{Cu}, \quad{ }^{64} \mathrm{Zn}(d, 2 p){ }^{64} \mathrm{Cu}$, ${ }^{66} \mathrm{Zn}(d, \alpha){ }^{64} \mathrm{Cu}$ and ${ }^{\text {nat }} \mathrm{Zn}(d, x){ }^{64} \mathrm{Cu}$, leading to the formation of no-carrier-added ${ }^{64} \mathrm{Cu}$ were considered. For each reaction, a critical evaluation of the excitation function was done. Therefrom recommended reaction cross section values for the production of ${ }^{64} \mathrm{Cu}$ were deduced. The experimental data were compared with results of three modern nuclear model calculations. As the nuclear interactions and level schemes are not completely understood, an adjustment of nuclear model parameters is invariably necessary to obtain a good agreement between the nuclear theory and experiments. On the other hand, nuclear model calculations can be applied to predict with confidence the results of a nuclear reaction without experimental data.

A recent study on therapeutic radionuclides under the auspices of a Coordinated Research Project (CRP) of the IAEA has also dealt with the evaluation of cross sections of several charged particle induced reactions leading to the formation of ${ }^{64} \mathrm{Cu}$ in no-carrier-added form ([16]; see also: Therapeutical radioisotopes production, http://www-nds.iaea.org/medportal/). The present work entails a much more detailed study; it incorporates all reactions and presents results of two nuclear model calculations (STAPRE and TALYS) not previously attempted in the above mentioned IAEA-CRP work.

\section{Normalization and selection of experimental data}

Seven nuclear processes investigated for production of ${ }^{64} \mathrm{Cu}$, alongwith their Q-values and references to experiments [17-41], are given in Table 1. The list is believed to include all references to date. We analysed the experimental details, wherever available. Almost all cross section measurements were done via the stacked-foil irradiation technique. Measurements done by using natural target materials, e.g. by Zweit et al. [29] and Takács et al. [30], were normalized in accordance with the abundance of the considered target isotope. The monitor reaction cross sections of the considered experiments were compared with the recommended data in the IAEA TECDOC-1211 [42]; however no significant discrepancies were observed. The cross sections reported by Levkovskij [25] were decreased by $20 \%$ for each considered proton induced reaction, in agreement with the new measurements for the ${ }^{\text {nat }} \operatorname{Mo}(p, x)^{96 \mathrm{~m}, \mathrm{~s}} \mathrm{Tc}$ monitor reaction by Takács et al. [43].

A further important factor in the normalization of cross section data is the consideration of the decay data used in obtaining the absolute activity of the radioactive product. This was especially important in the case of ${ }^{64} \mathrm{Cu}$ where some discrepancies in the decay data existed. Recently the $\beta^{+}$and

Table 1. Investigated nuclear reactions for the production of ${ }^{64} \mathrm{Cu}$, Q-values and references.

\begin{tabular}{|c|c|c|}
\hline Nuclear reaction & $\begin{array}{l}\text { Q-value } \\
(\mathrm{MeV})\end{array}$ & References \\
\hline${ }^{64} \mathrm{Ni}(p, n){ }^{64} \mathrm{Cu}$ & -2.46 & $\begin{array}{l}\text { Blaser et al., } 1951 \text { [17]; Blosser and Handley, } 1955 \text { [18]; } \\
\text { Tanaka et al., } 1959 \text { [19], } 1972 \text { [20]; Treytl and Caretto, } \\
1966 \text { [21]; Guzhovskij et al., } 1969 \text { [22]; Nemashkalo et al., } \\
1983 \text { [23]; Sevior et al., } 1983 \text { [24]; Levkovskij, } 1991 \text { [25]; } \\
\text { Antropov et al., } 1992 \text { [26]; Szelecsényi et al., 1993 [12]; } \\
\text { Avila et al., } 2007 \text { [27]; Rebeles } \text { et al., } 2009 \text { [28] }\end{array}$ \\
\hline${ }^{64} \mathrm{Ni}(d, 2 n){ }^{64} \mathrm{Cu}$ & -4.68 & $\begin{array}{l}\text { Zweit et al., } 1991 \text { [29]; Takács et al., } 2007 \text { [30]; } \\
\text { Hermanne et al., } 2007 \text { [31]; Daraban et al., 2009 [32] }\end{array}$ \\
\hline${ }^{68} \mathrm{Zn}(p, \alpha n){ }^{64} \mathrm{Cu}$ & -7.79 & $\begin{array}{l}\text { Levkovskij, } 1991 \text { [25]; Hilgers et al., } 2003 \text { [33]; } \\
\text { Szelecsényi et al., } 2005 \text { [35], } 2008 \text { [36] }\end{array}$ \\
\hline${ }^{66} \mathrm{Zn}(p, 2 p n){ }^{64} \mathrm{Cu}$ & -18.8 & Szelecsényi, et al., 2005 [35], 2008 [36] \\
\hline${ }^{64} \mathrm{Zn}(d, 2 p){ }^{64} \mathrm{Cu}$ & -2.02 & Williams and Irvine 1963 [37]; Daraban et al., 2008 [38] \\
\hline${ }^{66} \mathrm{Zn}(d, \alpha){ }^{64} \mathrm{Cu}$ & 7.24 & $\begin{array}{l}\text { Williams and Irvine, } 1963 \text { [37]; Hilgers, et al., } 2003 \text { [33], } \\
2005 \text { [34] }\end{array}$ \\
\hline $\begin{array}{l}\text { nat } \mathrm{Zn}(d, x)^{64} \mathrm{Cu} \text {, } \\
\text { including }\end{array}$ & & $\begin{array}{l}\text { Hilgers et al., } 2003 \text { [33]; Bonardi et al., } 2003 \text { [39]; } \\
\text { Groppi } \text { et al., } 2004 \text { [40]; Tárkányi et al., } 2004 \text { [41] }\end{array}$ \\
\hline${ }^{64} \mathrm{Zn}(d, 2 p){ }^{64} \mathrm{Cu}$ & -2.02 & \\
\hline${ }^{66} \mathrm{Zn}(d, \alpha){ }^{64} \mathrm{Cu}$ & 7.24 & \\
\hline${ }^{67} \mathrm{Zn}(d, \alpha n){ }^{64} \mathrm{Cu}$ & 0.18 & \\
\hline${ }^{68} \mathrm{Zn}(d, \alpha 2 n){ }^{64} \mathrm{Cu}$ & -10.0 & \\
\hline
\end{tabular}


$\gamma$-ray emission intensities were accurately determined by Qaim et al. [44]. The cross sections measured by using the value of $19 \%$ for the positron emission intensity [29,33-35] were increased by $7 \%$ in view of the new value of $17.8 \%$. The new value for $\gamma$-ray intensity $\left(I_{\gamma}=0.54 \%\right.$, instead of $0.47 \%$ ) necessitated a decrease of $15 \%$ for the cross section measurements done by detecting the weak $1346 \mathrm{keV}$ $\gamma$-ray $[27,28,30-32,35,39-41]$. In case of very old measurements with no reported information about decay data and/or monitor reactions, no normalization was performed [17-20, 22-24, 26, 37].

\section{Evaluation procedure}

The normalized experimental data were compared with the results of nuclear model calculations using three codes, namely STAPRE, EMPIRE and TALYS. The model parameters were adjusted to get a better agreement between the experimental and calculated cross section values. The estimation of the best set of cross section data was obtained by multiplying the nuclear model calculations with the normalization factor, which was based on the ratio of measured to calculated cross section (i.e. measurement/calculation). An iterative approach was applied for the best approximation of the normalization factor. In this approach a rational function was fitted over the measurement/calculation ratio for all the available data to describe the deviation between experiment and theory. The data points beyond the $3 \sigma$ limit were neglected. For the fitting procedure the default polynomial fitting tool of Origin 7.5 software was used. In the next step, the procedure was repeated with the remaining data and points outside the $3 \sigma$ limit were deselected. These iterations were performed until a normalization factor based on the measurements within $3 \sigma$ limit was generated. The product of that normalization function and model calculation provided the best estimation of cross section values.

The above described procedure was followed for each nuclear model calculation (i.e. STAPRE, EMPIRE and TALYS). At the end, based on the best estimations from each nuclear model, a recommended set of cross section values was obtained. The uncertainties of the measurements were also taken into account and are shown by $95 \%$ confidence limits in each case.

\section{Nuclear model calculations}

Nuclear model calculations were performed using the codes STAPRE, EMPIRE and TALYS. Some of the important features of those codes are mentioned below:

\section{STAPRE}

This is one of the oldest codes and was developed at the Institut für Radiumforschung und Kernphysik in Vienna $[45,46]$. It has been extensively used for data development and reaction mechanisms studies under JülichDebrecen collaboration [47-49]. The code uses the statistical model incorporating also pre-equilibrium effects in the framework of the exciton model [50]. The first chance emission from the equilibrated system is treated by the width fluctuation corrected Hauser-Feshbach formula [51]. In all the calculations direct reaction contribution was excluded; it is very small as checked from the calculations by the TALYS and EMPIRE codes. The SCAT2 code [52] was used to generate the particle transmission coefficients with the optical model parameters from RIPL-2 [53]. The dependence of the average effective squared matrix element $|M|^{2}$ on mass number $(A)$ and excitation energy $(E)$ is defined [54] by the expression $|M|^{2}=F M \cdot A^{-3} \cdot E^{-1}$, where $F M$ is an adjustable parameter. All the gamma ray strength functions were obtained from the Weiskopff model, except for $E_{1}$ transitions, where the Brink-Axel model $[55,56]$ was used.

For level densities the back-shifted Fermi gas model [57] was used. The discrete level schemes of the product nuclei were taken from the information available in the ENSDF database of the National Nuclear Data Center (NNDC), Brookhaven National Laboratory (BNL), USA, whereas levels were treated as continuum at higher energies. The level density parameters in some calculations were adjusted $( \pm 20 \%)$ to get a better agreement with the measurements. The ratio of effective to rigid body moment of inertia $\left(\eta=\Theta_{\text {eff }} / \Theta_{\text {rig }}\right.$ ) defines the spin distribution of the level density. It is an important factor in calculations of isomeric cross sections. However, in all the calculations in this work, $\eta=1.0$ was used.

\section{EMPIRE 2.19}

The nuclear reaction code system, EMPIRE 2.19, has been designed to perform nuclear reaction calculations over a wide range of energies and incident particles. The covered energy range is from resonance region $(\sim \mathrm{keV})$ to several hundreds of $\mathrm{MeV}$, and the projectile could be any nucleon, ion (including heavy ion) or a photon. EMPIRE is equipped with a complex system of codes to describe all the important nuclear reaction mechanisms [58]. The optical model and the direct reaction calculations were performed by the ECIS-03 code [59]. The optical model, discrete levels and deformation parameters were retrieved from the RIPL-2 library [53]. The direct channel calculations were performed by using the coupled channels model or the distorted wave Born approximation (DWBA) method.

EMPIRE contains both the quantum mechanical (MSD/ MSC) and classical models (DEGAS, PCROSS, HMS) to describe pre-equilibrium reactions. ORION and TRISTAN codes based on the work of Tamura et al. [60] are employed in EMPIRE to perform calculations for multi-step direct (MSD) reactions. The multi-step compound (MSC) calculations involve the approach of NVWY theory [61], whereas $\gamma$-emission treatment is considered as in [62]. Both MSD and MSC are coupled together for quantum mechanical treatment of pre-equilibrium processes. EMPIRE also contains the DEGAS module based on the exciton model for description of pre-equilibrium reactions with angular momentum conservation [63]. Pre-equilibrium emission can also be considered using the PCROSS code, which includes nucleon, gamma and cluster emissions. The option of EMPIRE-specific level densities was selected for all the calculations. In all the reaction calculations discrete level schemes were adjusted by using the FITLEV option. An improved version of the Hauser-Feshbach theory was used for 
compound nucleus reactions. The width fluctuation corrections were based on HRTW model [64]. The gamma transitions were described by the Brink-Axel hypothesis.

\section{TALYS}

TALYS, a nuclear reaction software developed at NRG Petten and CEA Bruyères-le-Châtel, provides a continuous and smooth description of nuclear reactions over a wide energy and mass range. Nuclear reactions induced by neutrons, protons, deuterons, tritons, helions, alphas and photons can be simulated in the $1 \mathrm{keV}$ to $200 \mathrm{MeV}$ energy range [65]. TALYS contains a vast database for nuclear structure and model parameters, mostly based on the IAEA Reference Input Parameter Library [53].

TALYS incorporates a number of nuclear models to analyse all the significant nuclear reaction mechanisms. The ECIS-06 code [59] was used to perform the optical model and direct reaction calculations. The default optical model potentials (OMPs) of TALYS for neutrons and protons are from the local and global parametrizations by Koning and Delaroche [66], whereas OMPs for deuterons, tritons, helions and alpha particles are based on the folding approach [67]. Depending on the structure of the nuclei, calculations for direct reactions can be performed by the coupled channel method, the distorted wave Born approximation (DWBA), the weak-coupling model, and a phenomenological model for the giant resonances description. In all the calculations the default options for the direct reactions were used.

The compound nucleus was treated within the framework of Hauser-Feshbach model [51] alongwith the width fluctuation correction model of Moldauer [68]. The preequilibrium reaction calculations were performed by the exciton model [69]. The phenomenological model of Kalbach [70] was incorporated for pre-equilibrium reactions involving particles (projectiles and ejectiles) with different mass and charge numbers and mechanisms like breakup, stripping, pick-up and knock-out.

Among the various options for level densities, the backshifted Fermi gas model [57] was used. In some cases the level density parameters for some nuclides were modified to get the improved fitting of experimental data. The discrete level schemes of important nuclei in each reaction were properly adjusted for better description of the lower energy region. The $\gamma$-ray strength functions were described by the Brink-Axel model, which was the default option for all the transitions except $\mathrm{E}_{1}$. The $\gamma$-ray strength function could be adjusted by the $G_{\text {norm }}$ parameter which acts as a multiplication factor for $\gamma$-ray transmission coefficients.

\section{Evaluation of production data for ${ }^{64} \mathrm{Cu}$}

\section{$5.1{ }^{64} \mathrm{Cu}$ production from ${ }^{64} \mathrm{Ni}$ target}

\subsection{1 ${ }^{64} \mathrm{Ni}(p, n){ }^{64} \mathrm{Cu}$}

As mentioned above, this reaction utilizing enriched ${ }^{64} \mathrm{Ni}$ as target material is extensively used for the production of ${ }^{64} \mathrm{Cu}$. The database for this reaction is fairly strong and 13 data sets reporting experimental cross sections were found in the literature (see Table 1). Enriched ${ }^{64} \mathrm{Ni}$ target was used in seven experiments, namely Treytl and Caretto [21]; Nemashkalo et al. [23]; Sevior et al. [24]; Levkovskij [25]; Antropov et al. [26]; Szelecsényi et al. [12] and Rebeles et al. [28], the rest of the measurements were done on ${ }^{\text {nat }} \mathrm{Ni}$ target, i.e. Blaser et al. [17]; Blosser and Handley [18]; Guzhovskij et al. [22]; Tanaka et al. [19,20] and AvilaRodriguez et al. [27].

The experiment by Blosser and Handley [18] contains only one value of cross section at $12 \mathrm{MeV}$ which is very high and with very large uncertainty (40\%). So this data point was deselected. The cross section measurements by Tanaka and Furukawa [19] show large discrepancies between 7.5 and $12 \mathrm{MeV}$; the cross section values are very high and do not follow the systematic trend of the excitation function. However, later measurements of Tanaka et al. [20] provide very consistent data which are 10-20\% lower than the earlier data and seem to be in agreement with the other experiments. The measurements by Treytl and Caretto [21] were conducted at energies above $100 \mathrm{MeV}$; therefore this work is not included in the evaluation. The reported partial $\gamma$-emission cross sections by Nemashkalo et al. [23] are not included in the compilation. The reported cross section values of Levkovskij [25] were decreased by $20 \%$ (see above). Nevertheless the cross section values remain higher and shifted to high energies. The recent measurements by Avila-Rodriguez et al. [27] and Rebeles et al. [28] were adjusted to the new $\gamma$-ray intensity value. The cross section values from all the measurements considered in the evaluation are shown in Fig. 1.

The calculations by the TALYS code were invoked by the default optical model potential (OMP) for proton [66]. However, to get a better agreement between the experimental and calculated cross sections some parameters were adjusted. The multipliers used for modified OMP were (rvadjust = 0.89 , avadjust $=0.95$, avdadjust $=0.89$ ). The $\gamma$-ray strength function was tuned by (gnorm $=1.2$ ). The average effective matrix element was adjusted by setting M2constant = 0.6 and the level density parameter for ${ }^{64} \mathrm{Cu}$ was set to 8.5 $\mathrm{MeV}^{-1}$.

The EMPIRE code calculations for the direct reactions were performed by the DWBA model with slight modification of the local optical model potential [66], the adjustments were the same as in TALYS. The options of multi-step direct (MSD) and multi-step compound (MSC) were executed for pre-equilibrium emission of protons. For neutron and cluster emission in pre-equilibrium reactions the value of PCROSS was set as 1.5 , and the single particle level density parameter (GTILNO) was multiplied by 0.7 . The level density parameters were also adjusted for ${ }^{64} \mathrm{Cu},{ }^{64} \mathrm{Ni}$ and ${ }^{61} \mathrm{Co}$ nuclei by the multipliers $0.8,1.2$ and 1.2 , respectively.

STAPRE calculations were simulated by the transmission coefficients generated from the SCAT2 code. The modified Koning-Delaroche OMP [66] (as in TALYS) for the incident proton was applied in SCAT2. The other OMPs used for neutrons, alphas and deuterons were of Wilmore and Hodgson [71]; McFadden and Satchler [72]; Koning and Delaroche [66], respectively. The STAPRE calculations were performed by using the level density parameters from the compilation of Dilg et al. [57]. If for certain nuclei the parameters were not available, estimated values from the values of neighboring isotopes were used. The effect- 

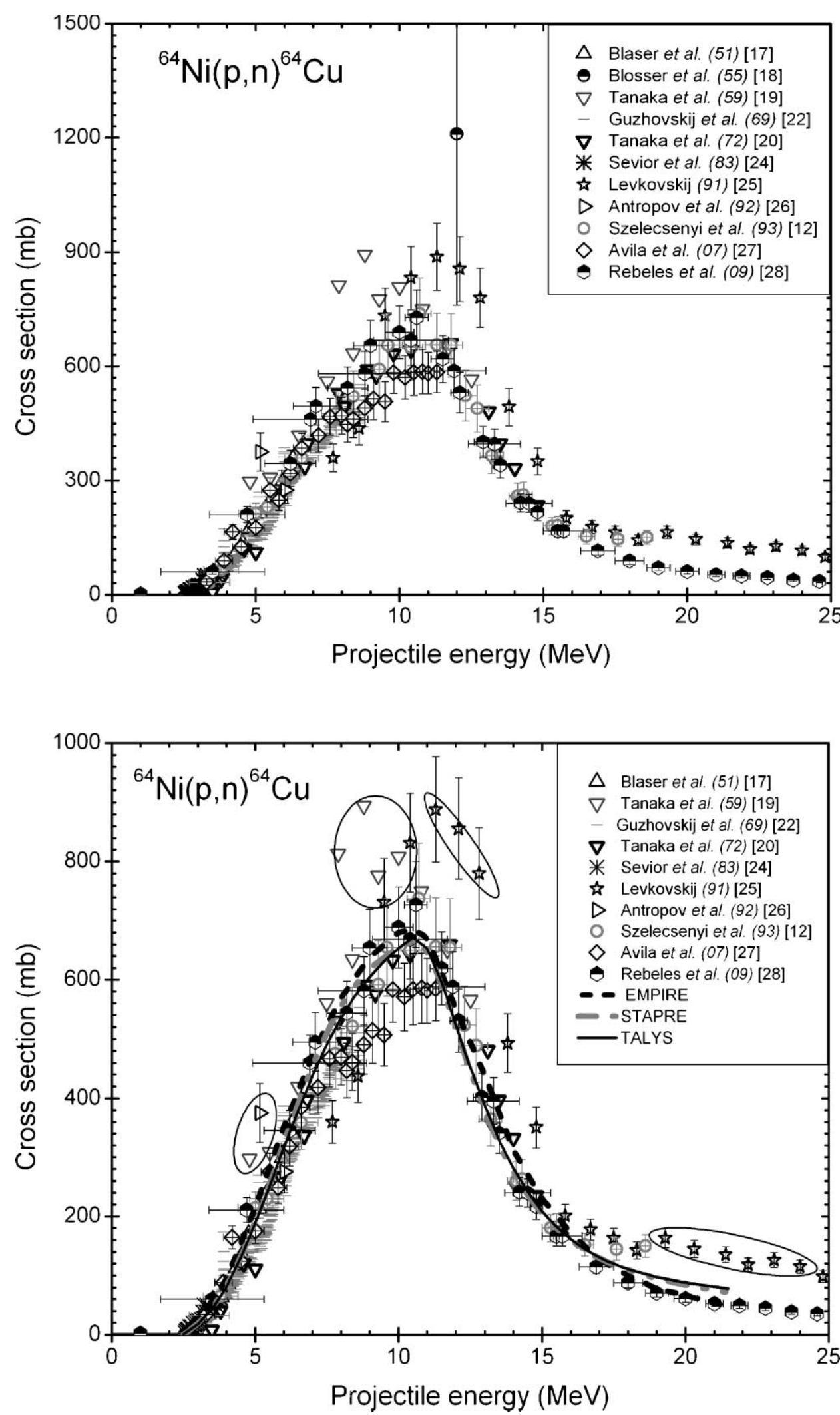

Fig. 1. All available normalized experimental data for the ${ }^{64} \mathrm{Ni}(p, n){ }^{64} \mathrm{Cu}$ reaction.
Fig. 2. Selected experimental data alongwith the results of calculations using the nuclear model codes (EMPIRE, STAPRE and TALYS) for the ${ }^{64} \mathrm{Ni}(p, n){ }^{64} \mathrm{Cu}$ reaction. The deselected data are encircled. ive squared matrix element was adjusted by setting $F M=$ $500 \mathrm{MeV}^{3}$.

The results of the nuclear model calculations are shown in Fig. 2, together with the normalized experimental data. There exists a good agreement among nuclear model calculations and the selected experimental data, except for some very discrepant measurements. The evaluation methodology described in Sect. 3 was then applied and the deviations between the measured and calculated cross sections for each code are depicted in Figs. 3 to 5. The polynomial functions, with $95 \%$ confidence limit, generated from these deviations are also represented. The data sets provided by the relationship between measurements and calculated cross sections were interpolated to get recommended cross section values. 


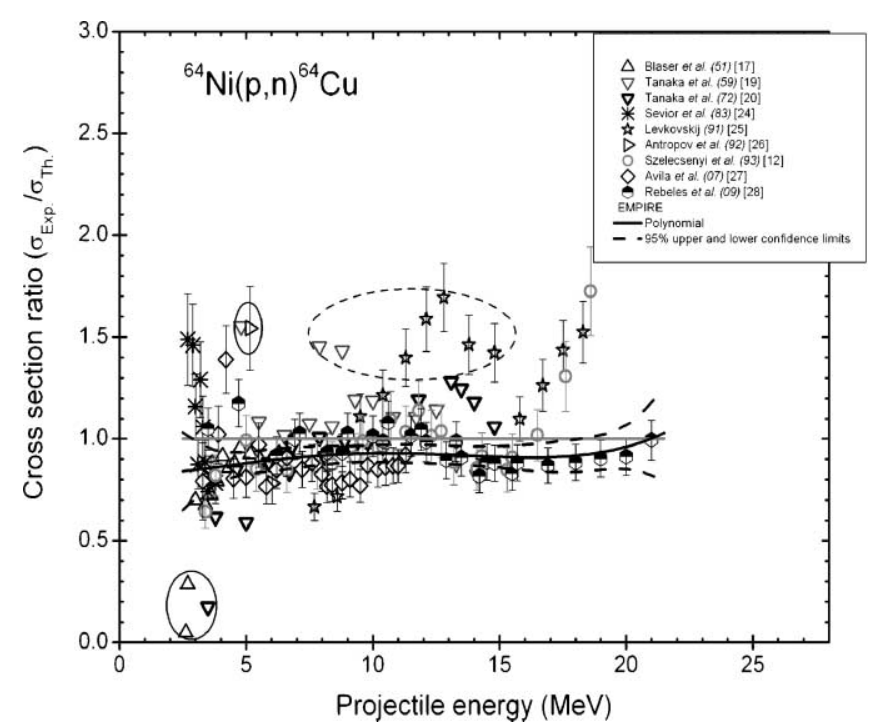

Fig. 3. Cross section ratios of the selected experimental data to model calculations by EMPIRE for the ${ }^{64} \mathrm{Ni}(p, n){ }^{64} \mathrm{Cu}$ reaction.

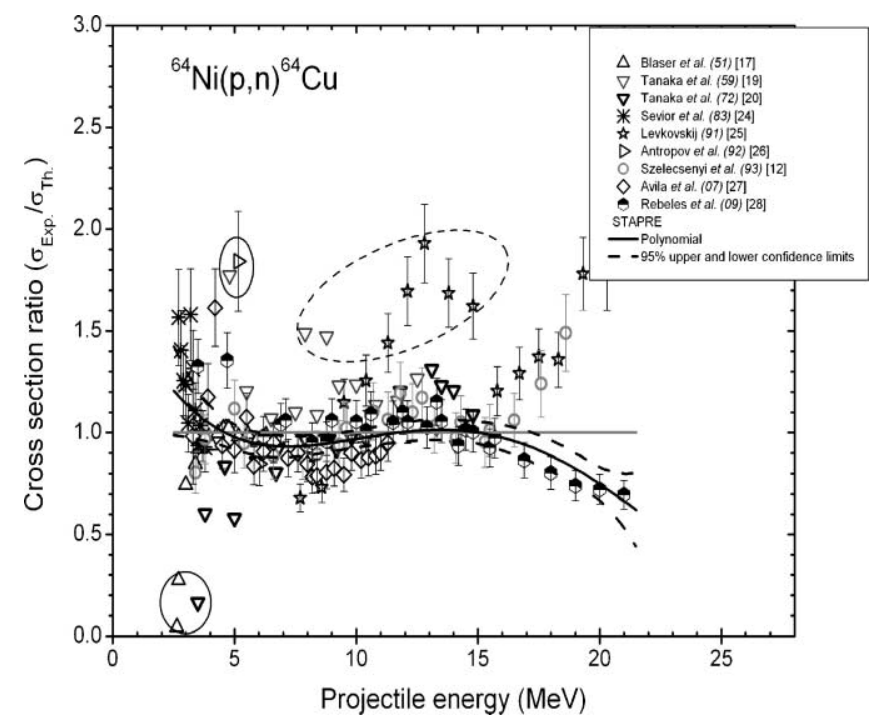

Fig. 4. Cross section ratios of the selected experimental data to model calculations by STAPRE for the ${ }^{64} \mathrm{Ni}(p, n){ }^{64} \mathrm{Cu}$ reaction.

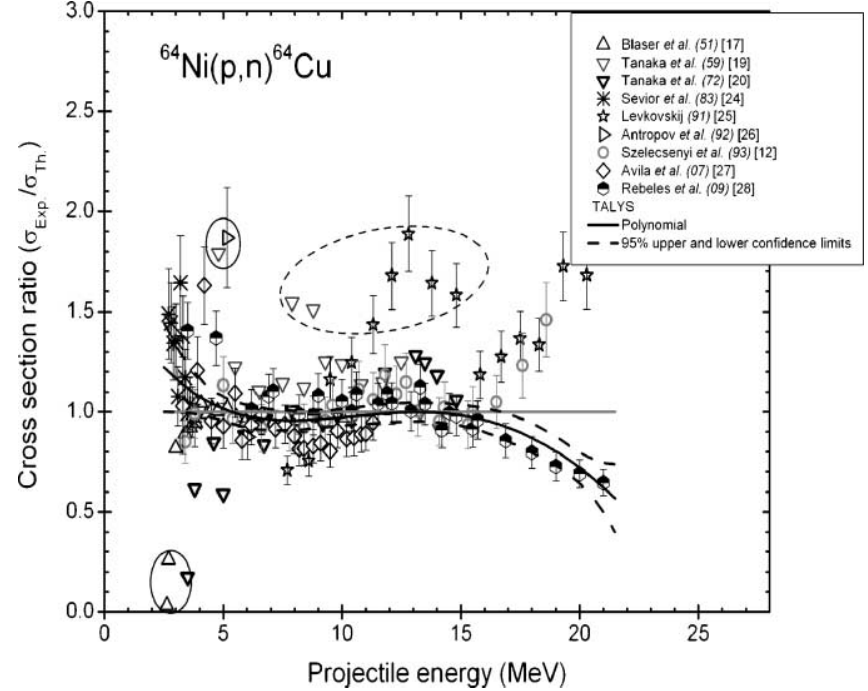

Fig. 5. Cross section ratios of the selected experimental data to model calculations by TALYS for the ${ }^{64} \mathrm{Ni}(p, n){ }^{64} \mathrm{Cu}$ reaction.

The recommended cross sections with $95 \%$ confidence limit are shown in Fig. 6. The numerical values are given in Table 2.

\subsection{2 ${ }^{64} \mathrm{Ni}(d, 2 n){ }^{64} \mathrm{Cu}$}

The amount of experimental cross section data available in the literature for this reaction is not very large. Only four data sets exist (cf. Table 1). In a recent experiment Daraban et al. [32] measured the cross sections using enriched ${ }^{64} \mathrm{Ni}$ as target, whereas natural nickel was used as target material in the measurements of Zweit et al. [29]; Takács et al. [30] and Hermanne et al. [31]. All the measurements required adjustment in accordance with the new reported decay data for ${ }^{64} \mathrm{Cu}$ (see above). The cross section measurements by Zweit et al. [29] are rather scanty and show an energy shift. The reported cross section values from enriched ${ }^{64} \mathrm{Ni}$ by Daraban et al. [32] are slightly higher than the measurements of Takács et al. [30] and Hermanne et al. [31]. All the meas-

Table 2. Recommended cross sections for the ${ }^{64} \mathrm{Ni}(p, n){ }^{64} \mathrm{Cu}$ reaction.

\begin{tabular}{|c|c|c|c|c|c|c|c|}
\hline \multirow{2}{*}{$E(\mathrm{MeV})$} & \multirow{2}{*}{$\sigma(\mathrm{mb})$} & \multicolumn{2}{|c|}{ 95\% confidence limits } & \multirow{2}{*}{$E(\mathrm{MeV})$} & \multirow{2}{*}{$\sigma(\mathrm{mb})$} & \multicolumn{2}{|c|}{$95 \%$ confidence limits } \\
\hline & & Upper & Lower & & & Upper & Lower \\
\hline 2.5 & 1.1 & 1.3 & 0.9 & 12.0 & 517 & 542 & 492 \\
\hline 3.0 & 20 & 23 & 17 & 12.5 & 452 & 474 & 430 \\
\hline 3.5 & 49 & 54 & 43 & 13.0 & 391 & 410 & 372 \\
\hline 4.0 & 85 & 93 & 78 & 13.5 & 333 & 349 & 316 \\
\hline 4.5 & 135 & 145 & 126 & 14.0 & 281 & 295 & 267 \\
\hline 5.0 & 190 & 201 & 178 & 14.5 & 242 & 254 & 229 \\
\hline 5.5 & 249 & 264 & 234 & 15.0 & 206 & 218 & 195 \\
\hline 6.0 & 310 & 328 & 292 & 15.5 & 179 & 190 & 168 \\
\hline 6.5 & 368 & 390 & 347 & 16.0 & 155 & 165 & 145 \\
\hline 7.0 & 424 & 448 & 401 & 16.5 & 136 & 146 & 127 \\
\hline 7.5 & 473 & 498 & 448 & 17.0 & 119 & 128 & 110 \\
\hline 8.0 & 517 & 543 & 492 & 17.5 & 106 & 115 & 98 \\
\hline 8.5 & 553 & 579 & 528 & 18.0 & 95 & 103 & 87 \\
\hline 9.0 & 585 & 611 & 559 & 18.5 & 86 & 93 & 78 \\
\hline 9.5 & 610 & 637 & 584 & 19.0 & 77 & 83 & 69 \\
\hline 10.0 & 633 & 660 & 605 & 19.5 & 70 & 77 & 63 \\
\hline 10.5 & 647 & 676 & 618 & 20.0 & 64 & 71 & 57 \\
\hline 11.0 & 634 & 663 & 604 & 20.5 & 57 & 65 & 49 \\
\hline 11.5 & 581 & 608 & 553 & 21.0 & 51 & 61 & 41 \\
\hline
\end{tabular}



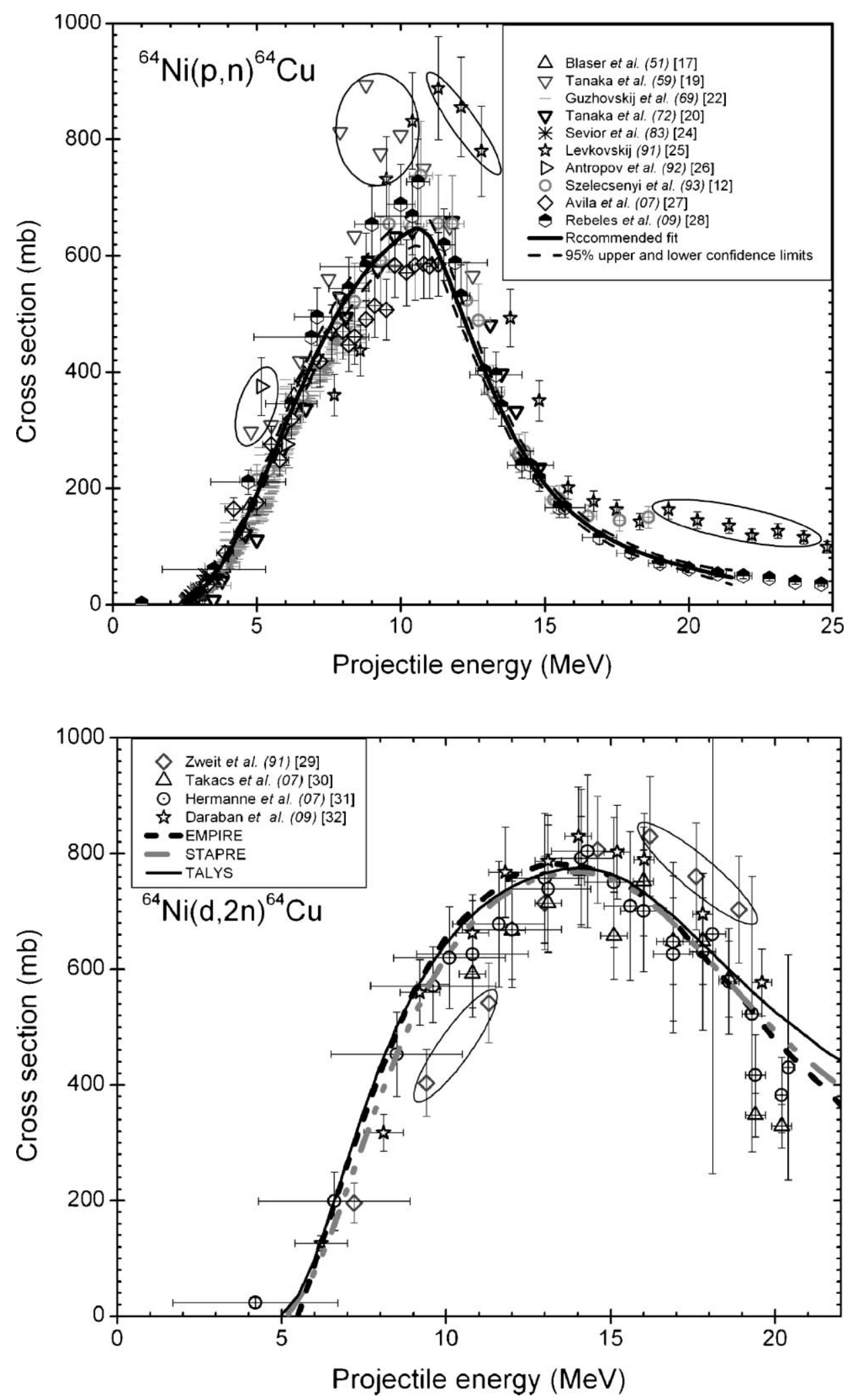

Fig. 6. Selected experimental data alongwith the recommended fit for the ${ }^{64} \mathrm{Ni}(p, n){ }^{64} \mathrm{Cu}$ reaction. The deselected data are encircled.

Fig. 7. All available normalized experimental data alongwith the results of calculations using the nuclear model codes (EMPIRE, STAPRE and TALYS) for the ${ }^{64} \mathrm{Ni}(d, 2 n){ }^{64} \mathrm{Cu}$ reaction. The deselected data are encircled.

urements have somewhat high uncertainties but show agreement within the limits of their uncertainties.

The nuclear model calculations by the TALYS code were simulated by the slightly modified default OMP for the deuteron. The modification factors used were (avdadjust $=$ 0.973 and rvdadjust $=1.035$ ). The level density parameters of ${ }^{64} \mathrm{Ni},{ }^{64} \mathrm{Cu}$ and ${ }^{65} \mathrm{Cu}$ were modified to $8.3,8.15$ and 8.7 $\mathrm{MeV}^{-1}$, respectively. The averaged squared matrix element was adjusted by setting M2constant $=1.2$.
The EMPIRE calculations were initiated with the OMP of Bojowald et al. [73] and DWBA model. Pre-equilibrium calculations were done by PCROSS module, with a value set to 1.3. The single particle level density was set to a value of 0.9. The multipliers used for level densities adjustment for ${ }^{65} \mathrm{Ni},{ }^{65} \mathrm{Cu}$ and ${ }^{64} \mathrm{Cu}$ were $1.2,0.8$ and 0.8 , respectively.

For the STAPRE calculations, the computer code SCAT2 was used to calculate the transmission coefficients. The OMPs for protons, neutrons and deuterons were from Kon- 
Table 3. Recommended cross sections for the ${ }^{64} \mathrm{Ni}(d, 2 n){ }^{64} \mathrm{Cu}$ reaction.

\begin{tabular}{|c|c|c|c|c|c|c|c|}
\hline \multirow[t]{2}{*}{$E(\mathrm{MeV})$} & \multirow{2}{*}{$\sigma(\mathrm{mb})$} & \multicolumn{2}{|c|}{ 95\% confidence limits } & \multirow[t]{2}{*}{$E(\mathrm{MeV})$} & \multirow{2}{*}{$\sigma(\mathrm{mb})$} & \multicolumn{2}{|c|}{$95 \%$ confidence limits } \\
\hline & & Upper & Lower & & & Upper & Lower \\
\hline 5.5 & 23 & 28 & 18 & 14.0 & 772 & 807 & 736 \\
\hline 6.0 & 87 & 102 & 73 & 14.5 & 773 & 808 & 738 \\
\hline 6.5 & 162 & 182 & 142 & 15.0 & 768 & 802 & 734 \\
\hline 7.0 & 241 & 263 & 219 & 15.5 & 756 & 790 & 722 \\
\hline 7.5 & 316 & 338 & 295 & 16.0 & 738 & 774 & 702 \\
\hline 8.0 & 388 & 408 & 368 & 16.5 & 714 & 751 & 676 \\
\hline 8.5 & 452 & 469 & 435 & 17.0 & 686 & 725 & 647 \\
\hline 9.0 & 511 & 525 & 496 & 17.5 & 652 & 691 & 612 \\
\hline 9.5 & 558 & 571 & 546 & 18.0 & 615 & 654 & 577 \\
\hline 10.0 & 603 & 616 & 589 & 18.5 & 578 & 614 & 541 \\
\hline 10.5 & 638 & 655 & 621 & 19.0 & 539 & 576 & 502 \\
\hline 11.0 & 670 & 692 & 647 & 19.5 & 497 & 541 & 455 \\
\hline 11.5 & 697 & 725 & 669 & 20.0 & 456 & 513 & 399 \\
\hline 12.0 & 721 & 754 & 689 & 20.5 & 418 & 499 & 337 \\
\hline 12.5 & 740 & 775 & 704 & 21.0 & 380 & 489 & 271 \\
\hline 13.0 & 756 & 793 & 719 & 21.5 & 345 & 474 & 215 \\
\hline 13.5 & 766 & 803 & 729 & 22.0 & 312 & 461 & 162 \\
\hline
\end{tabular}

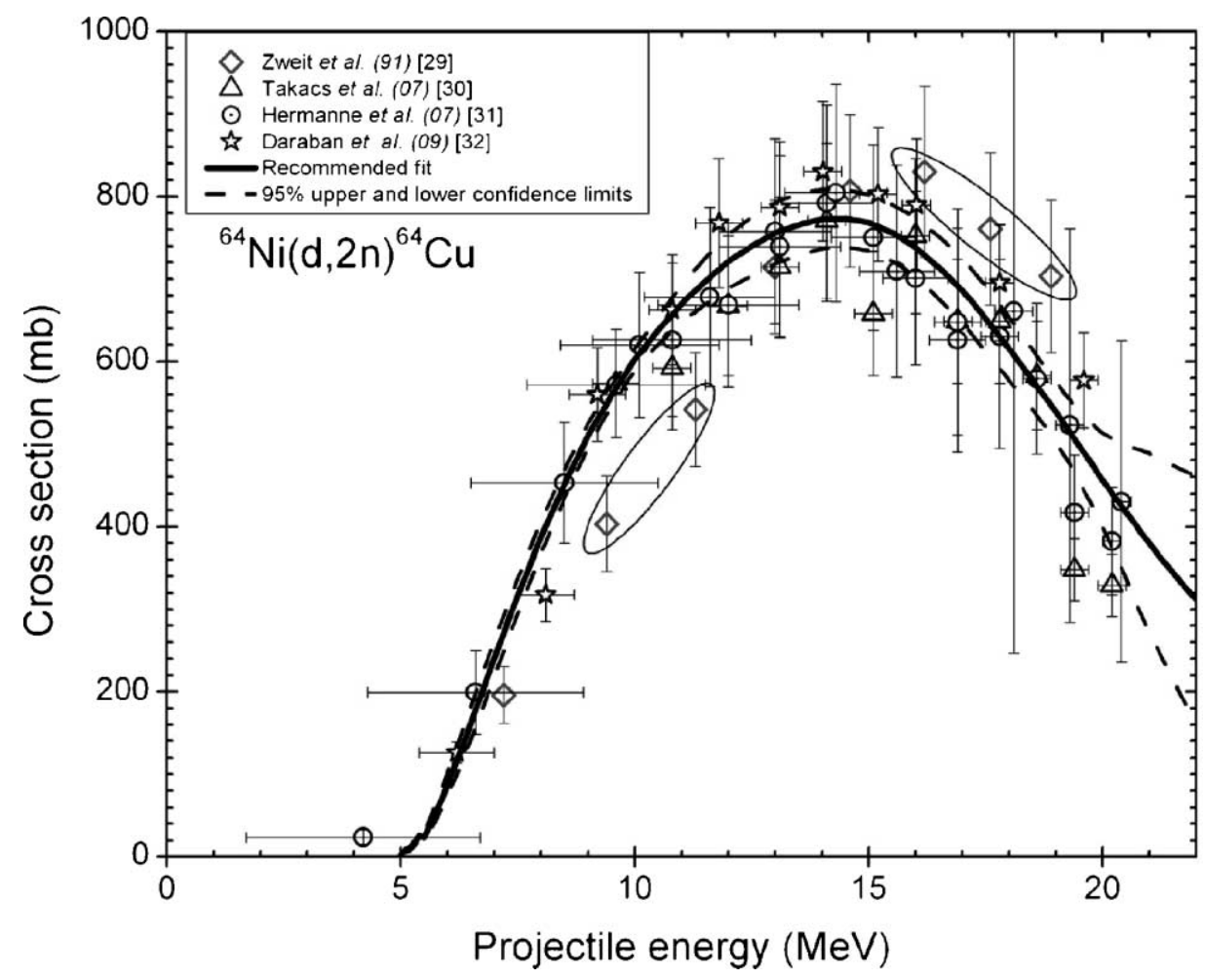

Fig. 8. Selected experimental data and recommended fit for the ${ }^{64} \mathrm{Ni}(d, 2 n){ }^{64} \mathrm{Cu}$ reaction. The deselected data are encircled. ing and Delaroche [66]. The deuteron OMP was slightly adjusted as in the case of TALYS calculations. The used OMP for the $\alpha$-particles was from McFadden and Satchler [72]. The value of $F M=250 \mathrm{MeV}^{3}$ was used to adjust the effective matrix element.

The normalized experimental data and the results of the nuclear model calculations are shown in Fig. 7. The trend of the measurements is reproduced well by the theoretical calculations. Following the applied evaluation procedure, based on the variations among measurements and calculations, polynomial functions with $95 \%$ confidence limit for the three model calculations were constructed (see above). The interpolations of those polynomials generated recommended cross section data with $95 \%$ confidence limit. The selected experimental cross sections and the recommended curve are shown in Fig. 8 and the recommended data in numerical form are given in Table 3 .

\section{$5.2{ }^{64} \mathrm{Cu}$ production by proton induced reactions on ${ }^{68} \mathrm{Zn}$ and ${ }^{66} \mathrm{Zn}$}

\subsection{1 ${ }^{68} \mathrm{Zn}(p, \alpha n){ }^{64} \mathrm{Cu}$}

The ${ }^{68} \mathrm{Zn}$ bombardment with proton induces two processes having different $\mathrm{Q}$-values which contribute to the production of ${ }^{64} \mathrm{Cu}$, i.e. ${ }^{68} \mathrm{Zn}(p, \alpha n){ }^{64} \mathrm{Cu}$ and ${ }^{68} \mathrm{Zn}(p, 2 p 3 n){ }^{64} \mathrm{Cu}$ reactions. There exist three cross section measurements in literature for this reaction (referenced in Table 1). Enriched ${ }^{68} \mathrm{Zn}$ was used as target material in all the experiments. The measurements by Hilgers et al. [33] and Szelecsényi et al. [35] 


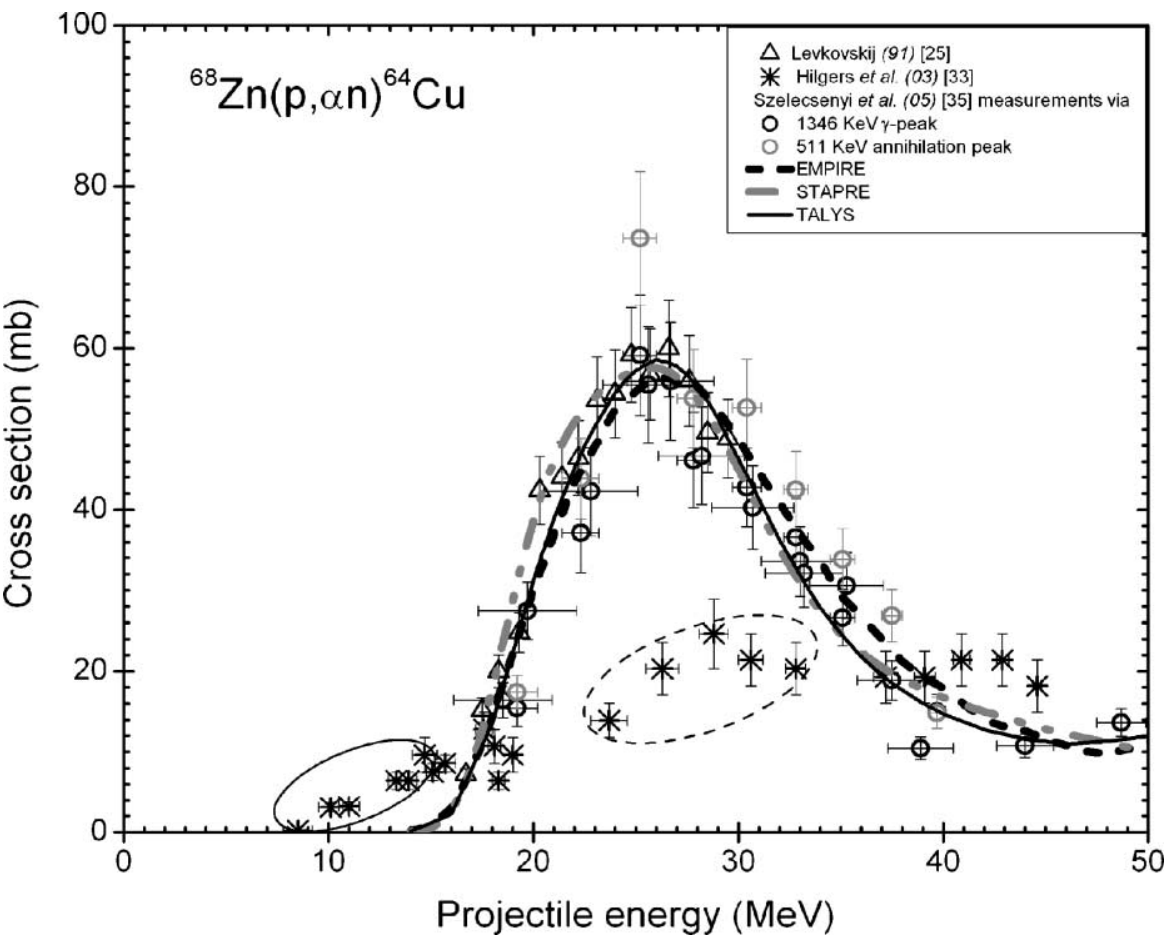

Fig. 9. All available normalized experimental data alongwith the results of calculations using the nuclear model codes (EMPIRE, STAPRE and TALYS) for the ${ }^{68} \mathrm{Zn}(p, \alpha n){ }^{64} \mathrm{Cu}$ reaction. The deselected data are encircled. were adjusted for new decay data and the work by Levkovskij [25] was normalized in accordance with the new monitor cross section values (see above). The cross section measurements by Hilgers et al. [33] are very discrepant in the 23 to $33 \mathrm{MeV}$ range. It is known now that the energy calibration in those experiments was faulty. Therefore the five data points in that energy range were not considered in further evaluation. The experiment by Szelecsényi et al. [35] contains cross section measurements upto $100 \mathrm{MeV}$. The activities determined via both the $1346 \mathrm{keV} \gamma$-ray and the $511 \mathrm{keV}$ annihilation radiation were used for cross section determination. Therefore the data were adjusted according to the new decay data of ${ }^{64} \mathrm{Cu}$.

The TALYS calculations for this reaction were executed by the Koning-Delaroche OMP [66]. The adjustments for the OMP parameter involved setting of (avadjust $=1.05$ ) for proton and (avadjust $=0.88$ ) for alpha particle. The matrix element was estimated by setting M2constant $=0.95$. The used level density parameter for ${ }^{68} \mathrm{Ga}$ was $8.9 \mathrm{MeV}^{-1}$.

In the case of EMPIRE code direct reaction contribution was calculated by the coupled channel method with the usual OMP [66]. The DEGAS code was activated for pre-equilibrium calculations. The cluster emission was taken into account by setting PCROSS $=1.2$, and for single particle level density GTILNO = 1.4 was used. The multipliers 1.2, 1.2, 1.2 and 0.9 were used for adjustments of level densities for ${ }^{68} \mathrm{Ga},{ }^{67} \mathrm{Ga},{ }^{68} \mathrm{Zn}$ and ${ }^{65} \mathrm{Cu}$, respectively.

The calculations by the SCAT2 code were performed by using the usual OMP [66] for proton. The OMPs for neutron, deuteron and alpha particle were taken from the same compilation. The OMPs for proton and alpha particle were modified as described in TALYS calculations. The generated transmission coefficients were used as input for calculations by the STAPRE code. The average matrix element was set by using the value of $F M=300 \mathrm{MeV}^{3}$.

The results of nuclear model calculations agree well with the measured cross sections within the limits of their uncer- tainties as shown in Fig. 9. Calculations were limited only up to about $50 \mathrm{MeV}$, since that is the region of interest for production of ${ }^{64} \mathrm{Cu}$. Beyond $50 \mathrm{MeV}$ the experimental cross section increases due to the onset of the ${ }^{68} \mathrm{Zn}(p, 2 p 3 n){ }^{64} \mathrm{Cu}$ process, and thus the yield of ${ }^{64} \mathrm{Cu}$ further increases, but since ${ }^{67} \mathrm{Cu}$ formation also starts at that energy $[36,74]$, we did not consider the higher energy region. Rational functions were established to fit the deviations between experimental data and each model calculation. The best data estimated from the relationship between measurements and calculations were interpolated to generate recommended cross section values with $95 \%$ confidence limit. The results are shown in Fig. 10 and the numerical values are given in Table 4.

\subsection{2 ${ }^{66} \mathrm{Zn}(p, 2 p n){ }^{64} \mathrm{Cu}$}

There exists only one measurement for this reaction by Szelecsényi et al. [35]. In this measurement highly enriched $(\geq 99 \%){ }^{66} \mathrm{Zn}$ was used as target. The cross section values were adjusted for the new $\gamma$-ray intensity of ${ }^{64} \mathrm{Cu}$ (see above). The reported cross sections are not of high quality but they show consistency within the limits of their uncertainties.

For this reaction the nuclear model calculation was done only using the code TALYS, which is more suitable in the high energy region. It was simulated by the default OMP [66]. The level density parameters for ${ }^{67} \mathrm{Ga},{ }^{65} \mathrm{Zn}$ and ${ }^{65} \mathrm{Cu}$ were set as 7.9, 7.6 and $7.5 \mathrm{MeV}^{-1}$, respectively. The value of M2constant was set as 1.2 for adjustment of averaged squared matrix element. The trend in the experimental values appears to be described well by the nuclear model calculation as shown in Fig. 11. The fit function based on fitting of deviation between measured and calculated values was used to extract the recommended cross section values. The experimental and recommended cross sections, along with $95 \%$ confidence limit, are shown in Fig. 12. The numerical values are given in Table 5 . 


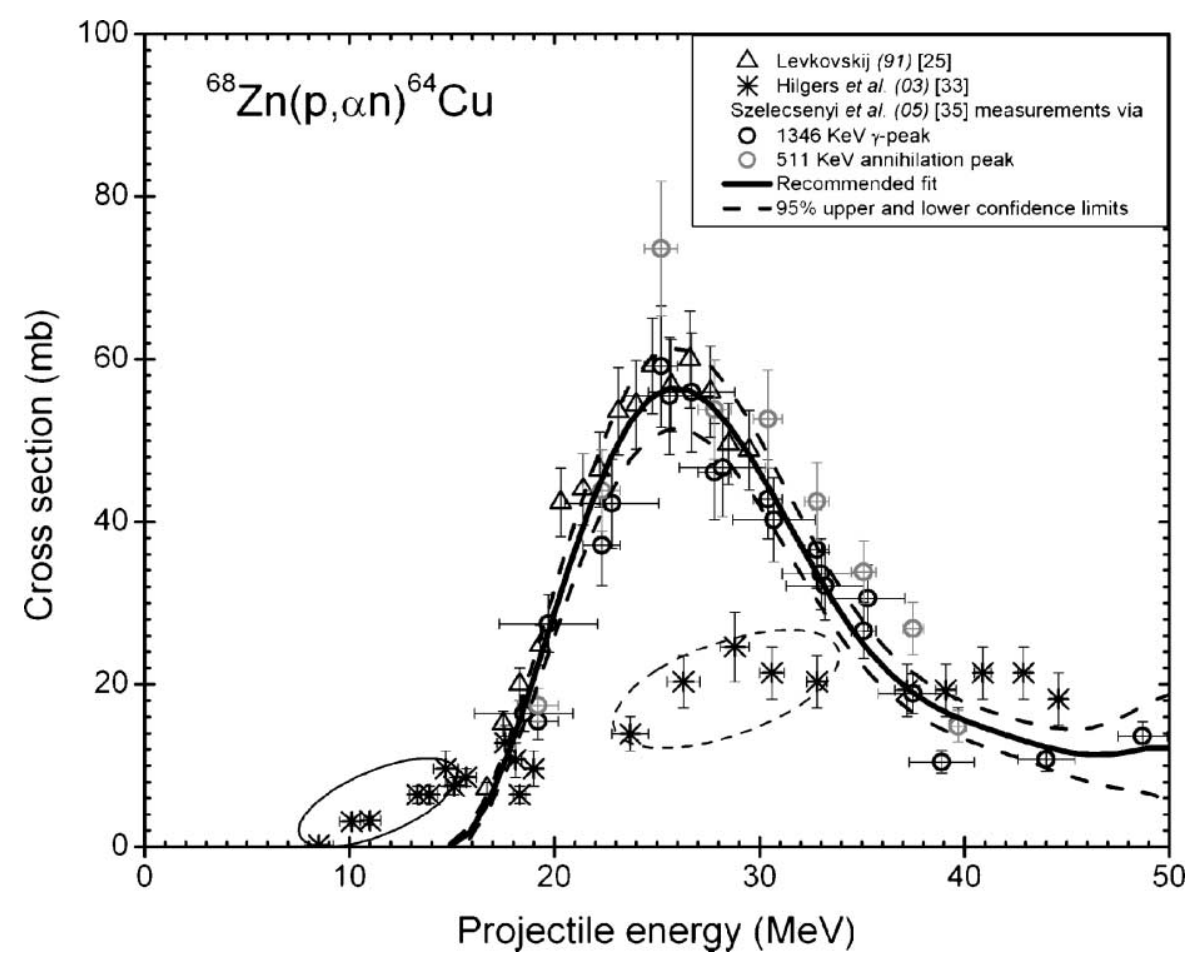

Fig. 10. Selected experimental data and recommended fit for the ${ }^{68} \mathrm{Zn}(p, \alpha n){ }^{64} \mathrm{Cu}$ reaction. The deselected data are encircled.

Table 4. Recommended cross sections for the ${ }^{68} \mathrm{Zn}(p, \alpha n){ }^{64} \mathrm{Cu}$ reaction.

\begin{tabular}{|c|c|c|c|c|c|c|c|}
\hline \multirow[t]{2}{*}{$E(\mathrm{MeV})$} & \multirow[t]{2}{*}{$\sigma(\mathrm{mb})$} & \multicolumn{2}{|c|}{ 95\% confidence limits } & \multirow[t]{2}{*}{$E(\mathrm{MeV})$} & \multirow[t]{2}{*}{$\sigma(\mathrm{mb})$} & \multicolumn{2}{|c|}{$95 \%$ confidence limits } \\
\hline & & Upper & Lower & & & Upper & Lower \\
\hline 16.0 & 2.4 & 3.1 & 1.5 & 29.5 & 48.2 & 52.4 & 43.9 \\
\hline 16.5 & 4.5 & 5.4 & 3.4 & 30.0 & 46.0 & 50.2 & 41.9 \\
\hline 17.0 & 6.9 & 8.1 & 5.6 & 30.5 & 43.9 & 47.9 & 39.9 \\
\hline 17.5 & 10.0 & 11.4 & 8.5 & 31.0 & 41.6 & 45.4 & 37.8 \\
\hline 18.0 & 13.3 & 15.0 & 11.6 & 31.5 & 39.3 & 43.0 & 35.7 \\
\hline 18.5 & 17.0 & 19.0 & 15.0 & 32.0 & 37.1 & 40.6 & 33.6 \\
\hline 19.0 & 20.8 & 23.1 & 18.69 & 32.5 & 34.8 & 38.2 & 31.5 \\
\hline 19.5 & 24.8 & 27.4 & 22.3 & 33.0 & 32.7 & 35.9 & 29.5 \\
\hline 20.0 & 28.8 & 31.7 & 25.9 & 33.5 & 30.6 & 33.7 & 27.5 \\
\hline 20.5 & 32.7 & 35.9 & 29.6 & 34.0 & 28.7 & 31.7 & 25.7 \\
\hline 21.0 & 36.5 & 40.0 & 33.1 & 34.5 & 26.8 & 29.7 & 24.0 \\
\hline 21.5 & 40.1 & 43.8 & 36.4 & 35.0 & 25.2 & 28.0 & 22.4 \\
\hline 22.0 & 43.4 & 47.4 & 39.4 & 36.0 & 22.3 & 24.9 & 19.7 \\
\hline 22.5 & 46.4 & 50.7 & 42.2 & 37.0 & 19.9 & 22.4 & 17.4 \\
\hline 23.0 & 49.0 & 53.4 & 44.6 & 38.0 & 18.1 & 20.5 & 15.7 \\
\hline 23.5 & 51.3 & 55.9 & 46.8 & 39.0 & 16.7 & 19.0 & 14.4 \\
\hline 24.0 & 53.1 & 57.8 & 48.4 & 40.0 & 15.5 & 17.8 & 13.3 \\
\hline 24.5 & 54.6 & 59.4 & 49.8 & 41.0 & 14.6 & 16.9 & 12.3 \\
\hline 25.0 & 55.5 & 60.4 & 50.7 & 42.0 & 13.8 & 16.1 & 11.5 \\
\hline 25.5 & 56.2 & 61.1 & 51.3 & 43.0 & 13.0 & 15.3 & 10.6 \\
\hline 26.0 & 56.3 & 61.2 & 51.4 & 44.0 & 12.2 & 14.8 & 9.7 \\
\hline 26.5 & 56.1 & 61.0 & 51.2 & 45.0 & 11.6 & 14.5 & 8.8 \\
\hline 27.0 & 55.4 & 60.3 & 50.6 & 46.0 & 11.3 & 14.6 & 8.0 \\
\hline 27.5 & 54.6 & 59.4 & 49.8 & 47.0 & 11.3 & 15.2 & 7.4 \\
\hline 28.0 & 53.3 & 57.9 & 48.6 & 48.0 & 11.7 & 16.3 & 7.0 \\
\hline 28.5 & 51.8 & 56.4 & 47.3 & 49.0 & 12.1 & 17.7 & 6.5 \\
\hline 29.0 & 50.0 & 54.4 & 45.6 & 50.0 & 12.1 & 18.7 & 5.6 \\
\hline
\end{tabular}

\section{$5.3{ }^{64} \mathrm{Cu}$ production by deuteron induced reactions on Zn targets}

\subsection{1 ${ }^{64} \mathrm{Zn}(d, 2 p){ }^{64} \mathrm{Cu}$}

The experimental cross section data reported for this reaction are scanty, only two data sets being available in the literature. Daraban et al. [38] used an enriched ${ }^{64} \mathrm{Zn}$ tar- get, whereas in earlier work by Williams and Irvine [37] the cross section values were deduced from measurements on ${ }^{\text {nat }} \mathrm{Zn}$. The data measured by Daraban et al. [38] appear to be consistent, except for a high cross section value at 17.4 MeV.

The default models of the TALYS code were used in calculations for this reaction. The only adjusted parame- 
Table 5. Recommended cross sections for the ${ }^{66} \mathrm{Zn}(p, 2 p n){ }^{64} \mathrm{Cu}$ reaction.

\begin{tabular}{|c|c|c|c|c|c|c|c|}
\hline \multirow[t]{2}{*}{$E(\mathrm{MeV})$} & \multirow[t]{2}{*}{$\sigma(\mathrm{mb})$} & \multicolumn{2}{|c|}{$95 \%$ confidence limits } & \multirow[t]{2}{*}{$E(\mathrm{MeV})$} & \multirow[t]{2}{*}{$\sigma(\mathrm{mb})$} & \multicolumn{2}{|c|}{$95 \%$ confidence limits } \\
\hline & & Upper & Lower & & & Upper & Lower \\
\hline 32.0 & 12.6 & 21.4 & 3.7 & 50.0 & 51.6 & 55.8 & 47.4 \\
\hline 32.5 & 15.9 & 24.4 & 7.5 & 52.0 & 47.7 & 51.7 & 43.7 \\
\hline 33.0 & 19.3 & 27.5 & 11.2 & 54.0 & 45.1 & 48.9 & 41.3 \\
\hline 33.5 & 22.7 & 30.5 & 14.9 & 56.0 & 43.6 & 47.2 & 39.9 \\
\hline 34.0 & 26.1 & 33.6 & 18.7 & 58.0 & 42.1 & 45.4 & 38.7 \\
\hline 34.5 & 29.6 & 36.6 & 22.6 & 60.0 & 40.0 & 43.0 & 36.9 \\
\hline 35.0 & 33.2 & 39.7 & 26.8 & 62.0 & 39.2 & 42.2 & 36.1 \\
\hline 35.5 & 36.9 & 43.2 & 30.5 & 64.0 & 38.8 & 42.1 & 35.5 \\
\hline 36.0 & 40.6 & 46.8 & 34.3 & 66.0 & 38.3 & 42.0 & 34.7 \\
\hline 36.5 & 44.0 & 50.1 & 37.9 & 68.0 & 37.8 & 41.9 & 33.7 \\
\hline 37.0 & 47.4 & 53.5 & 41.3 & 70.0 & 37.1 & 41.5 & 32.8 \\
\hline 37.5 & 50.3 & 56.6 & 44.0 & 72.0 & 38.0 & 42.8 & 33.3 \\
\hline 38.0 & 53.4 & 59.8 & 46.9 & 74.0 & 38.8 & 43.8 & 33.9 \\
\hline 38.5 & 56.0 & 62.6 & 49.4 & 76.0 & 39.2 & 44.3 & 34.2 \\
\hline 39.0 & 58.4 & 65.2 & 51.6 & 78.0 & 39.0 & 44.2 & 33.8 \\
\hline 39.5 & 60.1 & 67.0 & 53.2 & 80.0 & 38.6 & 44.0 & 33.2 \\
\hline 40.0 & 61.7 & 68.7 & 54.7 & 82.0 & 38.1 & 44.0 & 32.3 \\
\hline 41.0 & 63.7 & 70.6 & 56.7 & 84.0 & 38.1 & 44.7 & 31.5 \\
\hline 42.0 & 64.7 & 71.4 & 57.9 & 86.0 & 38.4 & 45.8 & 31.1 \\
\hline 43.0 & 64.2 & 70.5 & 57.8 & 88.0 & 37.5 & 45.3 & 29.7 \\
\hline 44.0 & 62.8 & 68.6 & 56.9 & 90.0 & 37.0 & 45.0 & 28.8 \\
\hline 45.0 & 61.4 & 66.8 & 56.0 & 92.0 & 36.0 & 44.1 & 27.7 \\
\hline 46.0 & 59.8 & 64.8 & 54.7 & 94.0 & 34.5 & 43.7 & 25.3 \\
\hline 47.0 & 56.9 & 61.6 & 52.3 & 96.0 & 32.5 & 45.1 & 19.9 \\
\hline 48.0 & 54.8 & 59.2 & 50.4 & 98.0 & 30.3 & 48.1 & 12.5 \\
\hline 49.0 & 53.0 & 57.3 & 48.8 & 100.0 & 28.3 & 51.2 & 5.3 \\
\hline
\end{tabular}

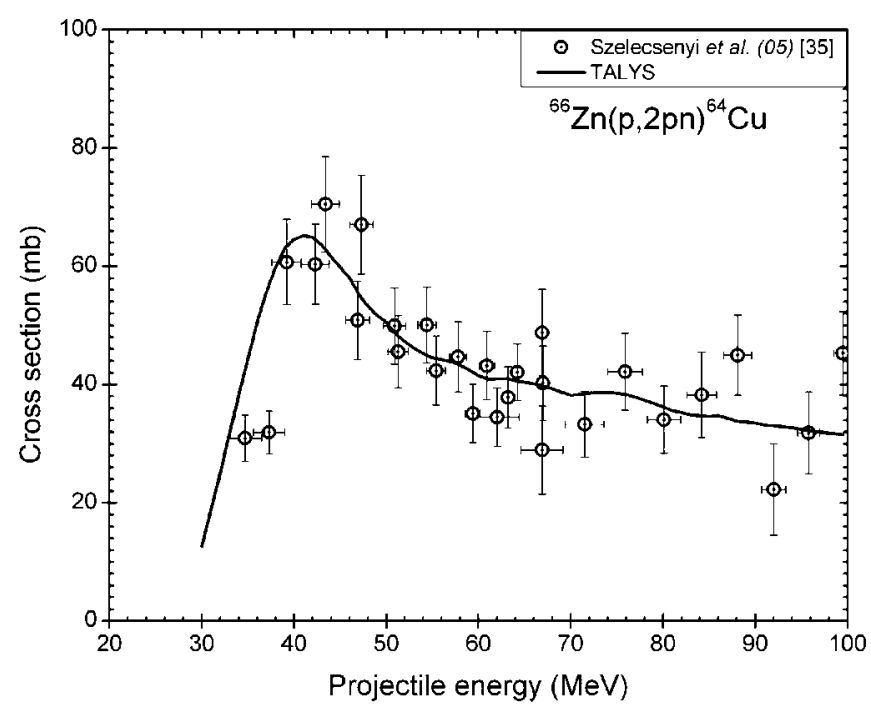

Fig. 11. Normalized experimental data alongwith the result of calculation using the nuclear model code TALYS for the ${ }^{66} \mathrm{Zn}(p, 2 p n){ }^{64} \mathrm{Cu}$ reaction.

ters were the level densities for ${ }^{64} \mathrm{Zn}$ and ${ }^{64} \mathrm{Cu}$ which were set as 7.6 and $8.0 \mathrm{MeV}^{-1}$, respectively. The coupled channel method with OMP of Bojowald et al. [73] was used in case of the EMPIRE calculation. The default PCROSS value (1.3) was used. The level densities of ${ }^{65} \mathrm{Ga}$ and ${ }^{64} \mathrm{Ga}$ were multiplied by 1.2 . The STAPRE calculations were performed by using the transmission coefficients calculated by the SCAT2 code. The used OMPs for the emitted particles were from Koning and Delaroche [66] for protons and deuterons, from Wilmore and Hodgson [71] for the neutrons and from McFadden and Satchler [72] for $\alpha$-particles. The

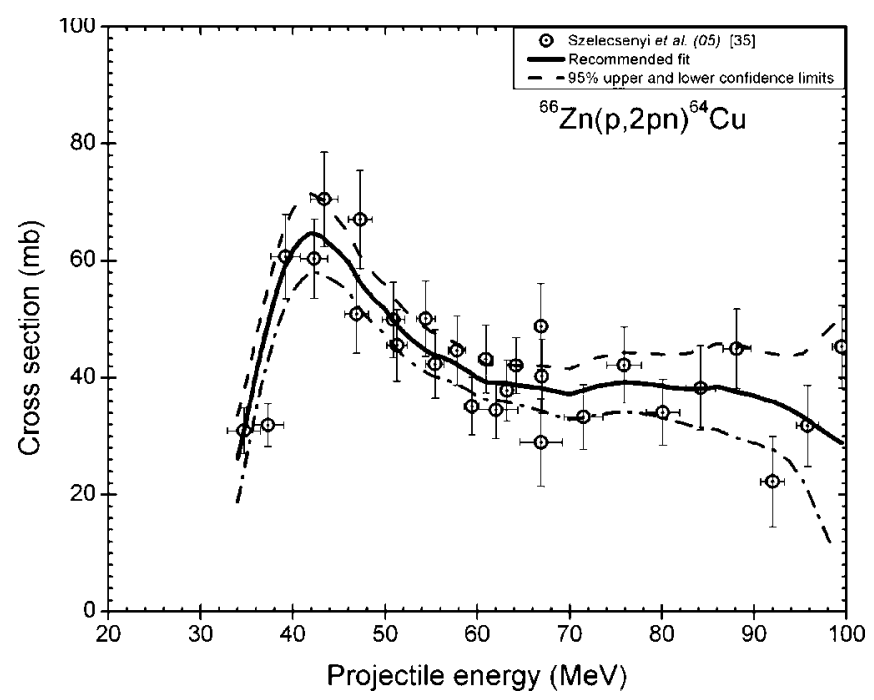

Fig. 12. Normalized experimental data and recommended fit for the ${ }^{66} \mathrm{Zn}(p, 2 p n){ }^{64} \mathrm{Cu}$ reaction.

average effective matrix element was estimated by setting $F M=450 \mathrm{MeV}^{3}$.

The experimental cross sections and the results of nuclear model calculations are shown in Fig. 13. There exists a good agreement between the measurements of Daraban et al. [38] and the nuclear model calculations, but the measurements of Williams and Irvine [37] are not supported by the calculations. The evaluation procedure described above was applied and the recommended curve based on the polynomials constructed from the relationship between measurements and nuclear model calculations is shown in Fig. 14; 
Table 6. Recommended cross sections for the ${ }^{64} \mathrm{Zn}(d, 2 p){ }^{64} \mathrm{Cu}$ reaction.

\begin{tabular}{|c|c|c|c|c|c|c|c|}
\hline \multirow[t]{2}{*}{$E(\mathrm{MeV})$} & \multirow[t]{2}{*}{$\sigma(\mathrm{mb})$} & \multicolumn{2}{|c|}{$95 \%$ confidence limits } & \multirow[t]{2}{*}{$E(\mathrm{MeV})$} & \multirow[t]{2}{*}{$\sigma(\mathrm{mb})$} & \multicolumn{2}{|c|}{$95 \%$ confidence limits } \\
\hline & & Upper & Lower & & & Upper & Lower \\
\hline 10.5 & 7.6 & 12.5 & 2.7 & 15.5 & 28.2 & 35.8 & 20.5 \\
\hline 11.0 & 9.2 & 14.7 & 3.6 & 16.0 & 30.6 & 38.8 & 22.4 \\
\hline 11.5 & 10.7 & 16.8 & 4.5 & 16.5 & 33.1 & 42.2 & 23.9 \\
\hline 12.0 & 12.3 & 19.0 & 5.5 & 17.0 & 35.4 & 45.9 & 24.9 \\
\hline 12.5 & 14.1 & 21.2 & 7.0 & 17.5 & 37.6 & 49.9 & 25.3 \\
\hline 13.0 & 16.1 & 23.3 & 8.9 & 18.0 & 39.6 & 54.4 & 24.9 \\
\hline 13.5 & 18.4 & 25.6 & 11.1 & 18.5 & 41.4 & 59.3 & 23.6 \\
\hline 14.0 & 20.7 & 27.9 & 13.5 & 19.0 & 43.0 & 64.7 & 21.3 \\
\hline 14.5 & 23.2 & 30.3 & 15.9 & 19.5 & 44.2 & 70.5 & 17.9 \\
\hline 15.0 & 25.6 & 32.9 & 18.3 & 20.0 & 45.5 & 76.5 & 14.4 \\
\hline
\end{tabular}

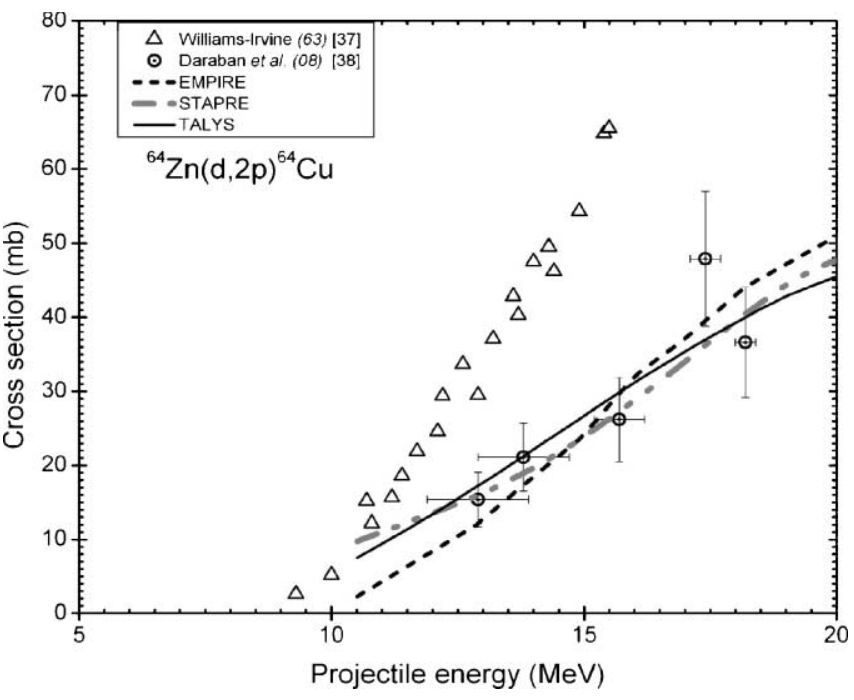

Fig. 13. Normalized experimental data alongwith the results of calculations using the nuclear model codes (EMPIRE, STAPRE and TALYS) for the ${ }^{64} \mathrm{Zn}(d, 2 p)^{64} \mathrm{Cu}$ reaction.

the numerical values of the recommended data are given in Table 6.

\subsection{2 ${ }^{66} \mathrm{Zn}(d, \alpha){ }^{64} \mathrm{Cu}$}

In the literature three cross section measurements exist for this reaction [33,34,37]. Hilgers et al. [33,34] used highly enriched ${ }^{66} \mathrm{Zn}$ as target, whereas cross section values given by Williams and Irvine [37] were extrapolated from the measurements on ${ }^{\text {nat }} \mathrm{Zn}$. The data sets by Hilgers et al. [33,34] were adjusted for new decay data of ${ }^{64} \mathrm{Cu}$, yet it provides too low cross sections, similar to the other measurements in the same experiment.

Regarding nuclear model calculations, the TALYS code was used with the default values. The adjusted level densities of ${ }^{67} \mathrm{Ga}$ and ${ }^{64} \mathrm{Cu}$ were 7.8 and $8.53 \mathrm{MeV}^{-1}$. The value of M2constant was set as 0.7. In the EMPIRE calculations the coupled channel model was used with the deuteron OMP [73]. The value of PCROSS was 1.4 and GTILNO was set as 1.3. The level densities of ${ }^{67} \mathrm{Ga},{ }^{67} \mathrm{Zn}$ and ${ }^{64} \mathrm{Cu}$ were multiplied by 1.2, 1.2 and 0.9 , respectively. In the case of STAPRE code, the transmission coefficients were generated by the SCAT2 code. The OMPs used for emission of different particles were from Becchetti and Greenlees [75] for protons, Wilmore and Hodgson [71] for neutrons, Lohr and

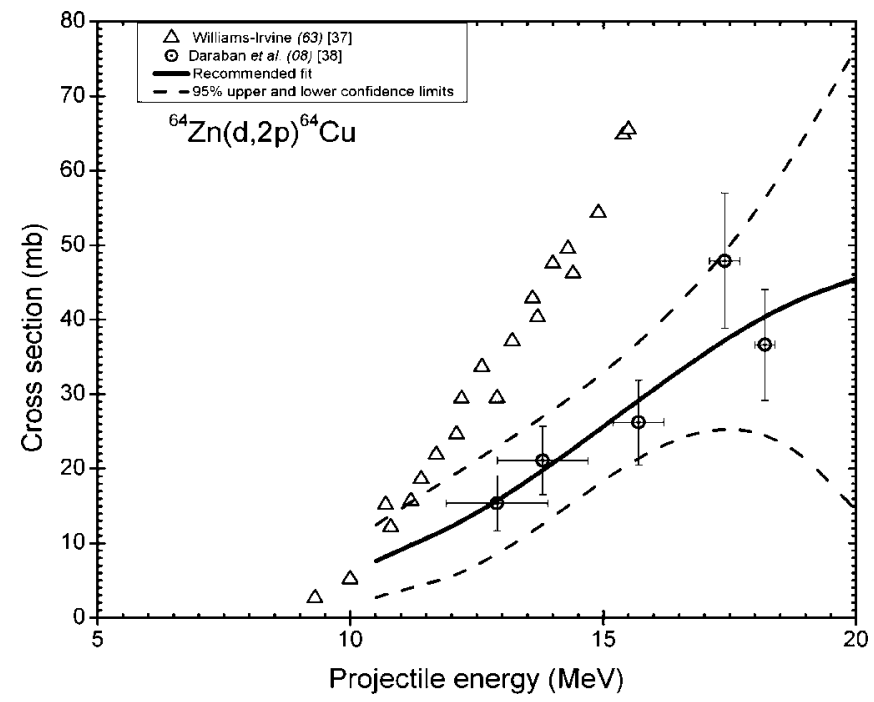

Fig. 14. Normalized experimental data and recommended fit for the ${ }^{64} \mathrm{Zn}(d, 2 p){ }^{64} \mathrm{Cu}$ reaction. The data by Williams and Irvine [37] were deselected.

Haeberli [76] for deuterons and McFadden and Satchler [72] for alphas. The $F M=500 \mathrm{MeV}^{3}$ was used for adjustment of the effective matrix element.

The experimental data and the results of nuclear model calculations for this reaction are shown in Fig. 15. The calculated results are consistent up to about $13 \mathrm{MeV}$; beyond that energy the STAPRE results, however, are rather low. In the threshold region the cross section values of Williams and Irvine [37] agree well with the nuclear model calculations, up to about $7 \mathrm{MeV}$, wheras those by Hilgers et al. $[33,34]$ show large deviations. In this case the recommendation of cross section data was entirely based on the nuclear model calculations. The predictions of the EMPIRE, STAPRE and TALYS code were interpolated by the polynomial function to obtain the recommended set of data. An uncertainty of $15 \%$ is assigned to account for the expected errors (Fig. 16). The numerical values are given in Table 7.

\subsection{3 ${ }^{\text {nat }} \mathrm{Zn}(d, x)^{64} \mathrm{Cu}$}

The radionuclide ${ }^{64} \mathrm{Cu}$ was produced in small amounts via this route more than 30 years ago [77]. Many reactions contribute to the formation of ${ }^{64} \mathrm{Cu}$ during the bombardment of ${ }^{n a t} \mathrm{Zn}$ by energetic deuterons. The major contributing reactions alongwith their Q-values are given in Table 1. Due to 
Table 7. Recommended cross sections for the ${ }^{66} \mathrm{Zn}(d, \alpha){ }^{64} \mathrm{Cu}$ reaction.

\begin{tabular}{|c|c|c|c|c|c|c|c|}
\hline \multirow[t]{2}{*}{$E(\mathrm{MeV})$} & \multirow[t]{2}{*}{$\sigma(\mathrm{mb})$} & \multicolumn{2}{|c|}{$95 \%$ confidence limits } & \multirow[t]{2}{*}{$E(\mathrm{MeV})$} & \multirow[t]{2}{*}{$\sigma(\mathrm{mb})$} & \multicolumn{2}{|c|}{$95 \%$ confidence limits } \\
\hline & & Upper & Lower & & & Upper & Lower \\
\hline 4.0 & 1.1 & 1.8 & 0.5 & 12.5 & 22.9 & 24.5 & 21.2 \\
\hline 4.5 & 6.7 & 7.4 & 6.0 & 13.0 & 21.1 & 22.7 & 19.6 \\
\hline 5.0 & 11.5 & 12.6 & 10.5 & 13.5 & 19.3 & 20.7 & 17.9 \\
\hline 5.5 & 15.7 & 17.1 & 14.3 & 14.0 & 17.4 & 18.8 & 16.1 \\
\hline 6.0 & 19.2 & 20.9 & 17.6 & 14.5 & 15.5 & 16.7 & 14.2 \\
\hline 6.5 & 22.1 & 24.0 & 20.3 & 15.0 & 13.5 & 14.7 & 12.3 \\
\hline 7.0 & 24.5 & 26.6 & 22.4 & 15.5 & 11.6 & 12.7 & 10.5 \\
\hline 7.5 & 26.3 & 28.5 & 24.2 & 16.0 & 9.8 & 10.9 & 8.7 \\
\hline 8.0 & 27.6 & 29.9 & 25.4 & 16.5 & 8.1 & 9.1 & 7.1 \\
\hline 8.5 & 28.5 & 30.8 & 26.2 & 17.0 & 6.5 & 7.4 & 5.6 \\
\hline 9.0 & 28.9 & 31.2 & 26.6 & 17.5 & 5.1 & 5.9 & 4.21 \\
\hline 9.5 & 28.9 & 31.1 & 26.7 & 18.0 & 3.9 & 4.6 & 3.2 \\
\hline 10.0 & 28.6 & 30.8 & 26.4 & 18.5 & 2.9 & 3.5 & 2.3 \\
\hline 10.5 & 27.9 & 30.0 & 25.9 & 19.0 & 2.3 & 2.8 & 1.7 \\
\hline 11.0 & 27.0 & 29.0 & 25.0 & 19.5 & 1.9 & 2.5 & 1.3 \\
\hline 11.5 & 25.8 & 27.7 & 23.9 & 20.0 & 1.9 & 2.8 & 1.1 \\
\hline 12.0 & 24.4 & 26.2 & 22.7 & & & & \\
\hline
\end{tabular}

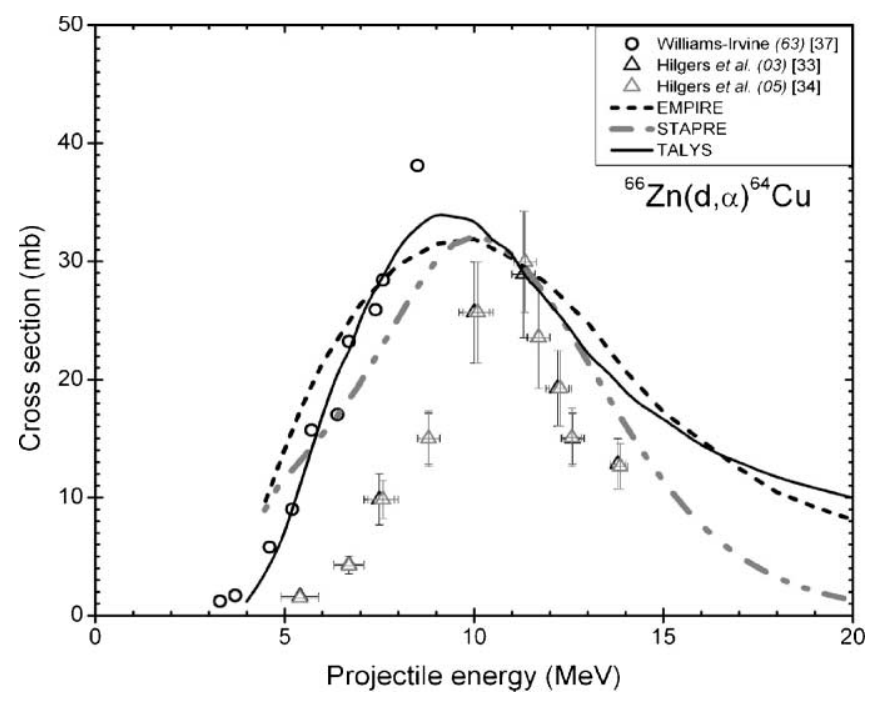

Fig. 15. Normalized experimental data alongwith the results of calculations using the nuclear model codes (EMPIRE, STAPRE and TALYS) for the ${ }^{66} \mathrm{Zn}(d, \alpha){ }^{64} \mathrm{Cu}$ reaction.

very small abundance of ${ }^{70} \mathrm{Zn}(0.6 \%)$ in ${ }^{\text {nat }} \mathrm{Zn}$, the cross sections of reactions induced on this target nuclide were not considered in the evaluation. The references to experimental cross section measurements [33,39-41] considered in the evaluation are also given in Table 1.

All the measured cross sections [33,39-41] were adjusted according to the new decay data of ${ }^{64} \mathrm{Cu}$ (see above). The data reported by Hilgers et al. [33] are very discrepant and inconsistent, particularly near the threshold of the reaction. The measured cross section data of Tárkányi et al. [41] have high uncertainties which are attributed to poor statistics. However, this work provides cross sections over a wide energy region, i.e. upto $50 \mathrm{MeV}$. In fact, there exist strong discrepancies among all the data sets as is evident from Fig. 17.

The code TALYS can perform nuclear reaction calculations for elements of natural isotopic composition. For these calculations the OMP for deuteron was modified by setting (rvadjust $=0.88$ and avadjust $=0.91$ ). The OMPs

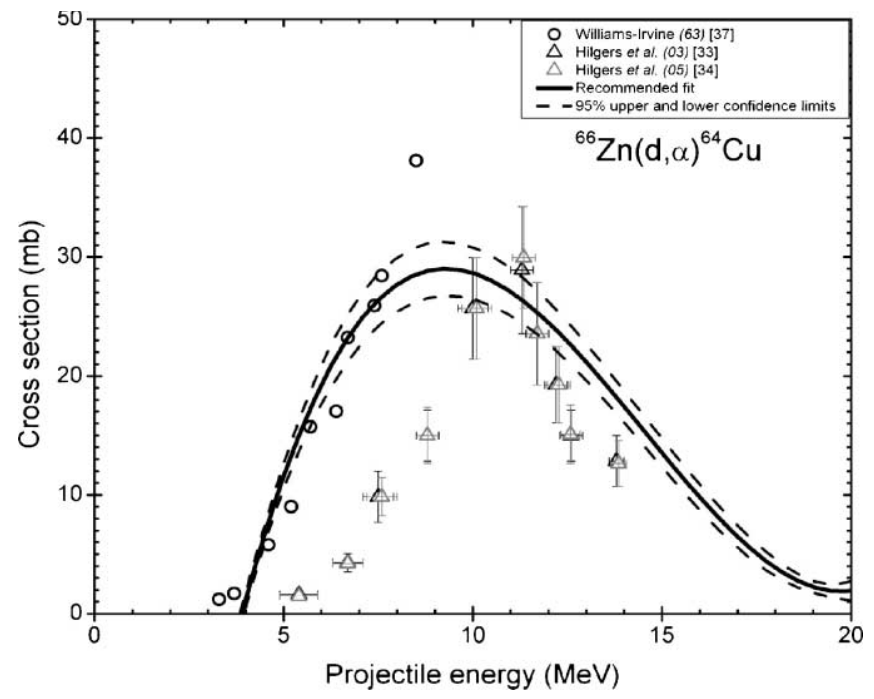

Fig. 16. Normalized experimental data and recommended fit for the ${ }^{66} \mathrm{Zn}(d, \alpha){ }^{64} \mathrm{Cu}$ reaction. The fit is entirely based on the nuclear model calculations (see text).

for the alpha particle and proton were also adjusted by setting (rvadjust $=0.93$ and avadjust $=1.13$, respectively). The used value of M2constant was 0.7. The EMPIRE calculations were performed for the deuteron induced reactions on all $\mathrm{Zn}$ isotopes, except ${ }^{70} \mathrm{Zn}$. Calculations were done for the ${ }^{64} \mathrm{Zn}(d, 2 p){ }^{64} \mathrm{Cu},{ }^{66} \mathrm{Zn}(d, x){ }^{64} \mathrm{Cu},{ }^{67} \mathrm{Zn}(d, x){ }^{64} \mathrm{Cu}$ and ${ }^{68} \mathrm{Zn}(d, x)^{64} \mathrm{Cu}$ reactions. In all the calculations the OMP of Bojowald et al. [73] was applied with coupled channel model. The value of PCROSS was set as 1.3 with single particle level density parameter GTILNO $=1.2$. For the ${ }^{64} \mathrm{Zn}(d, 2 p){ }^{64} \mathrm{Cu}$ reaction the level densities of ${ }^{65} \mathrm{Ga}$ and ${ }^{64} \mathrm{Ga}$ were multiplied by 1.2. The level densities for ${ }^{67} \mathrm{Ga}$ and ${ }^{66} \mathrm{Ga}$ were multiplied by 1.2 whereas for ${ }^{67} \mathrm{Zn},{ }^{66} \mathrm{Zn}$ and ${ }^{65} \mathrm{Cu}$ the used multiplier was 0.8 in the ${ }^{66} \mathrm{Zn}(d, x)^{64} \mathrm{Cu}$ reaction calculations. The level densities of ${ }^{68} \mathrm{Ga}$ and ${ }^{65} \mathrm{Cu}$ were multiplied by 1.2 and 0.8 , respectively, in case of the ${ }^{67} \mathrm{Zn}(d, x)^{64} \mathrm{Cu}$ reaction. The level density multipliers in the ${ }^{68} \mathrm{Zn}(d, x)^{64} \mathrm{Cu}$ reaction were 1.2 for ${ }^{69} \mathrm{Ga},{ }^{68} \mathrm{Ga}$ and ${ }^{67} \mathrm{Ga}$, and 0.8 for ${ }^{66} \mathrm{Cu}$ and ${ }^{65} \mathrm{Cu}$. The cross section values from all $\mathrm{Zn}$ isotope tar- 
Table 8. Recommended cross sections for the ${ }^{\text {nat }} \mathrm{Zn}(d, x){ }^{64} \mathrm{Cu}$ reaction.

\begin{tabular}{|c|c|c|c|c|c|c|c|}
\hline \multirow[t]{2}{*}{$E(\mathrm{MeV})$} & \multirow{2}{*}{$\sigma(\mathrm{mb})$} & \multicolumn{2}{|c|}{$95 \%$ confidence limits } & \multirow[t]{2}{*}{$E(\mathrm{MeV})$} & \multirow[t]{2}{*}{$\sigma(\mathrm{mb})$} & \multicolumn{2}{|c|}{$95 \%$ confidence limits } \\
\hline & & Upper & Lower & & & Upper & Lower \\
\hline 5.0 & 0.3 & 1.2 & 0.02 & 27.0 & 43.4 & 48.7 & 38.1 \\
\hline 6.0 & 3.1 & 3.4 & 2.8 & 28.0 & 43.3 & 48.7 & 37.9 \\
\hline 7.0 & 5.8 & 5.9 & 5.8 & 29.0 & 43.1 & 48.5 & 37.6 \\
\hline 8.0 & 8.7 & 8.9 & 8.6 & 30.0 & 42.8 & 48.2 & 37.2 \\
\hline 9.0 & 11.6 & 11.7 & 11.5 & 31.0 & 42.3 & 47.7 & 36.8 \\
\hline 10.0 & 14.5 & 14.6 & 14.5 & 32.0 & 41.7 & 47.1 & 36.2 \\
\hline 11.0 & 17.4 & 17.6 & 17.3 & 33.0 & 41.0 & 46.5 & 35.6 \\
\hline 12.0 & 20.3 & 20.8 & 19.9 & 34.0 & 40.4 & 45.9 & 34.9 \\
\hline 13.0 & 23.1 & 23.9 & 22.4 & 35.0 & 39.7 & 45.2 & 34.3 \\
\hline 14.0 & 25.8 & 26.9 & 24.7 & 36.0 & 39.1 & 44.7 & 33.7 \\
\hline 15.0 & 28.3 & 29.9 & 26.8 & 37.0 & 38.6 & 44.3 & 33.2 \\
\hline 16.0 & 30.7 & 32.7 & 28.8 & 38.0 & 38.3 & 44.1 & 32.7 \\
\hline 17.0 & 32.9 & 35.2 & 30.5 & 39.0 & 38.1 & 44.1 & 32.3 \\
\hline 18.0 & 34.9 & 37.7 & 32.1 & 40.0 & 38.2 & 44.4 & 32.1 \\
\hline 19.0 & 36.8 & 39.9 & 33.5 & 41.0 & 38.6 & 45.2 & 32.1 \\
\hline 20.0 & 38.4 & 41.9 & 34.7 & 42.0 & 39.3 & 46.4 & 32.3 \\
\hline 21.0 & 39.8 & 43.6 & 35.7 & 43.0 & 40.6 & 48.2 & 32.8 \\
\hline 22.0 & 40.9 & 45.1 & 36.6 & 44.0 & 42.2 & 50.7 & 33.5 \\
\hline 23.0 & 41.8 & 46.3 & 37.2 & 46.0 & 47.1 & 57.7 & 36.1 \\
\hline 24.0 & 42.5 & 47.2 & 37.7 & 48.0 & 55.1 & 68.7 & 40.6 \\
\hline 25.0 & 43.0 & 48.0 & 38.0 & 49.0 & 60.3 & 75.8 & 43.6 \\
\hline 26.0 & 43.3 & 48.4 & 38.1 & 50.0 & 66.4 & 84.0 & 47.2 \\
\hline
\end{tabular}

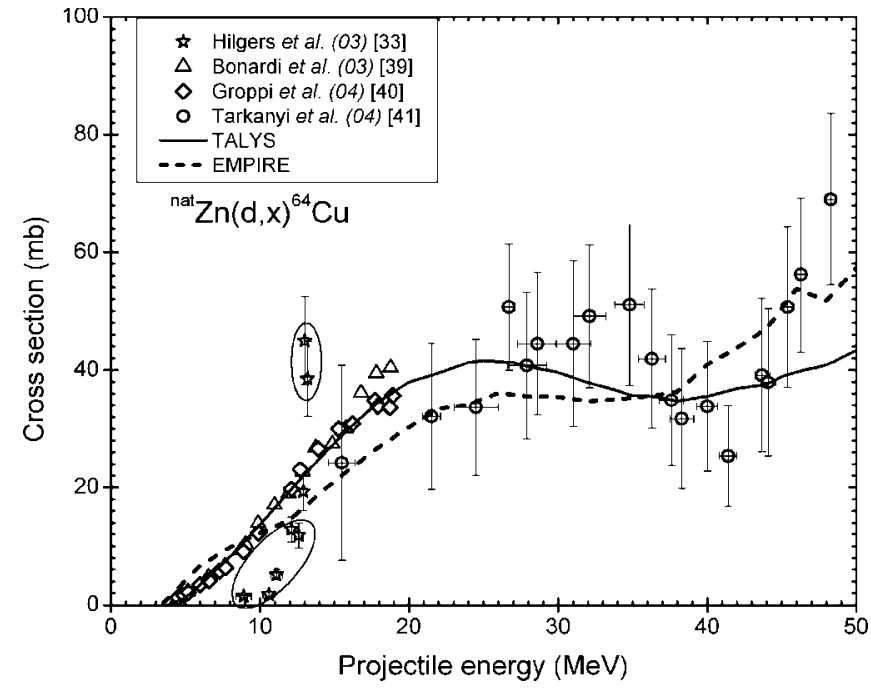

Fig. 17. Normalized experimental data alongwith the results of calculations using the nuclear model codes (EMPIRE and TALYS) for the ${ }^{\text {nat }} \mathrm{Zn}(d, x){ }^{64} \mathrm{Cu}$ reaction. The deselected data are encircled.

gets were summed in the ratio of their abundances in natural target to get the set of cross section data for deuteron induced reaction on ${ }^{\text {nat }} \mathrm{Zn}$.

The results of the nuclear model calculations are shown with the measured cross sections in Fig. 17. A reasonable agreement exists between the measurements and the calculations using the EMPIRE code. However, the TALYS code provides a very good description of the trend of the experimental data. The deviation of each experiment from calculated cross sections was determined to define a polynomial function. From those polynomials the recommended cross section values for this reaction were deduced and are depicted in Fig. 18. The numerical data are given in Table 8.

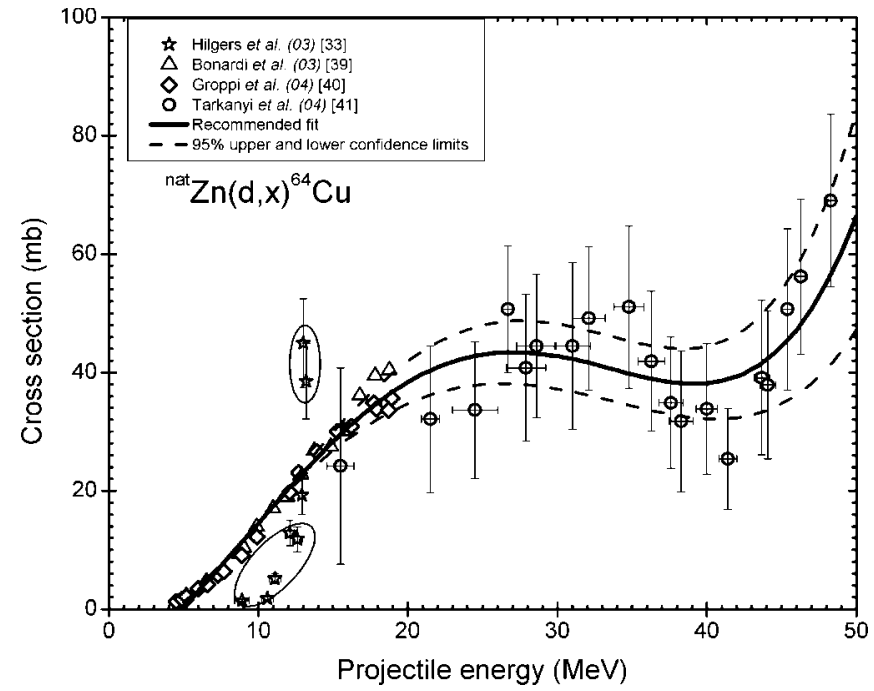

Fig. 18. Selected experimental data and recommended fit for the ${ }^{n a t} \mathrm{Zn}(d, x){ }^{64} \mathrm{Cu}$ reaction. The deselected data are encircled.

\section{Calculation of integral yields: Application of evaluated data}

A comprehensive analysis of the available experimental information on the excitation functions of the reactions ${ }^{64} \mathrm{Ni}(p, n){ }^{64} \mathrm{Cu},{ }^{64} \mathrm{Ni}(d, 2 n){ }^{64} \mathrm{Cu},{ }^{68} \mathrm{Zn}(p, \alpha n){ }^{64} \mathrm{Cu}$, ${ }^{66} \mathrm{Zn}(p, 2 p n){ }^{64} \mathrm{Cu}, \quad{ }^{64} \mathrm{Zn}(d, 2 p){ }^{64} \mathrm{Cu}, \quad{ }^{66} \mathrm{Zn}(d, \alpha){ }^{64} \mathrm{Cu}$ and ${ }^{n a t} \mathrm{Zn}(d, x)^{64} \mathrm{Cu}$, and their comparison with results of several nuclear model calculational codes, has led to recommended data sets for those reactions. Those data could now be confidently used for calculation of integral yield of ${ }^{64} \mathrm{Cu}$ via a given reaction over a certain energy range. We give the calculated yields for the above seven reactions in Figs. 19 to 23, together with the confidence limits. 


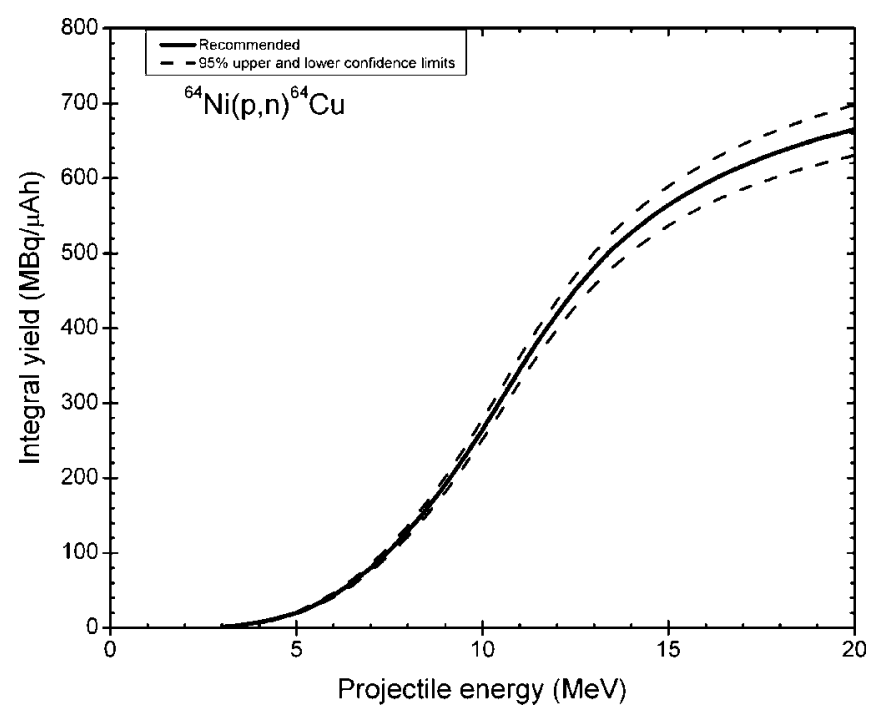

Fig. 19. Calculated integral yield for the ${ }^{64} \mathrm{Ni}(p, n){ }^{64} \mathrm{Cu}$ reaction.

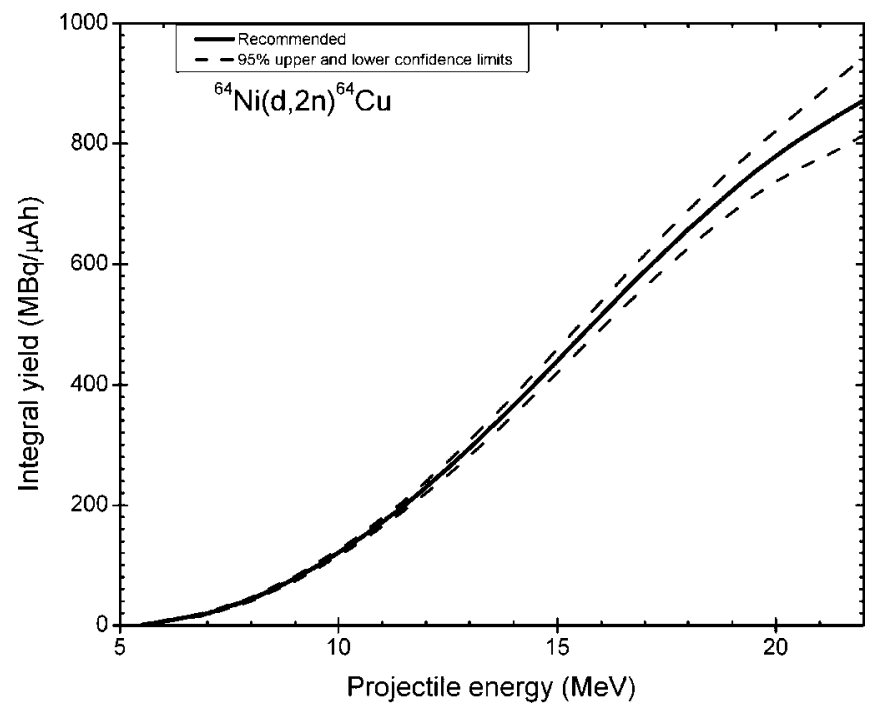

Fig. 20. Calculated integral yield for the ${ }^{64} \mathrm{Ni}(d, 2 n){ }^{64} \mathrm{Cu}$ reaction.

These yield values, in general, should be more accurate than the ones reported by authors from their own individual measurements.

It is interesting to compare the calculated yield in a reaction with some experimental yields determined under high current irradiation production conditions, if available. For the ${ }^{64} \mathrm{Ni}(p, n){ }^{64} \mathrm{Cu}$ reaction five groups, namely Nickles [78], McCarthy et al. [13], Szajek et al. [14], Obata et al. [79] and Avila-Rodriguez et al. [27], reported experimental ${ }^{64} \mathrm{Cu}$ yields. Those values are appreciably lower than the theoretical values. In the case of ${ }^{64} \mathrm{Zn}(d, 2 p){ }^{64} \mathrm{Cu}$ reaction Abbas et al. [80] and Kozempel et al. [81], and for the ${ }^{\text {nat }} \mathrm{Zn}(d, x)^{64} \mathrm{Cu}$ process Abbas et al. [82] reported experimental yields which are within the limits of the calculated yields. Experimental ${ }^{64} \mathrm{Cu}$ yields were also measured for the ${ }^{68} \mathrm{Zn}(p, \alpha n){ }^{64} \mathrm{Cu}$ process by Boothe et al. [83] and Smith et al. [84] and the values were considerably lower than the calculated yields. The reasons for low experimental yields are well known (loss of activity during irradiation and chemical processing, uncertainty in high beam current measurement, radiation damage, etc.; for more discussion cf. for

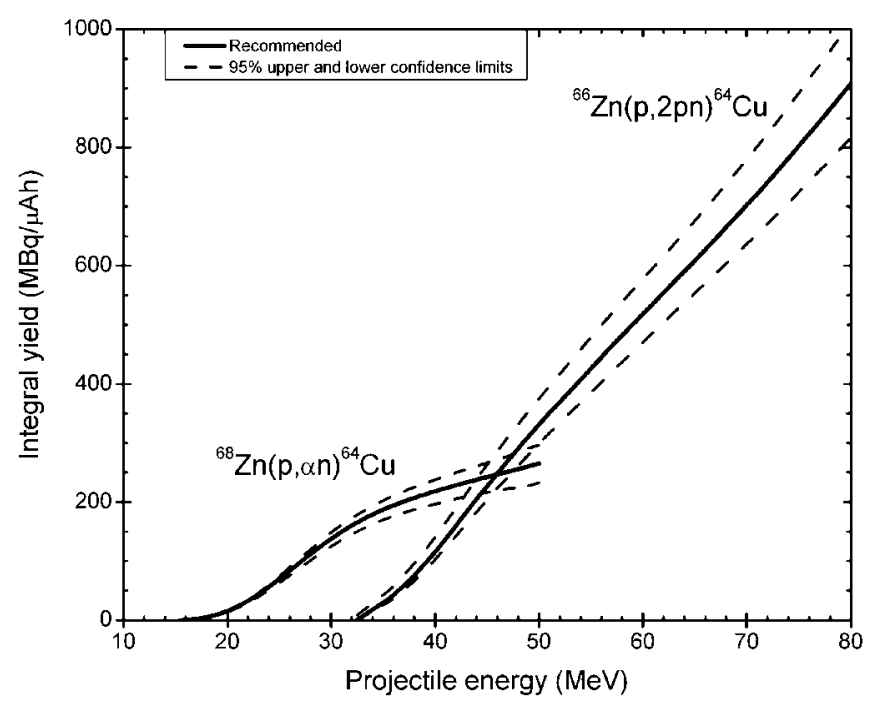

Fig. 21. Calculated integral yields for the ${ }^{68} \mathrm{Zn}(p, \alpha n)^{64} \mathrm{Cu}$ and ${ }^{66} \mathrm{Zn}(p, 2 p n){ }^{64} \mathrm{Cu}$ reactions.

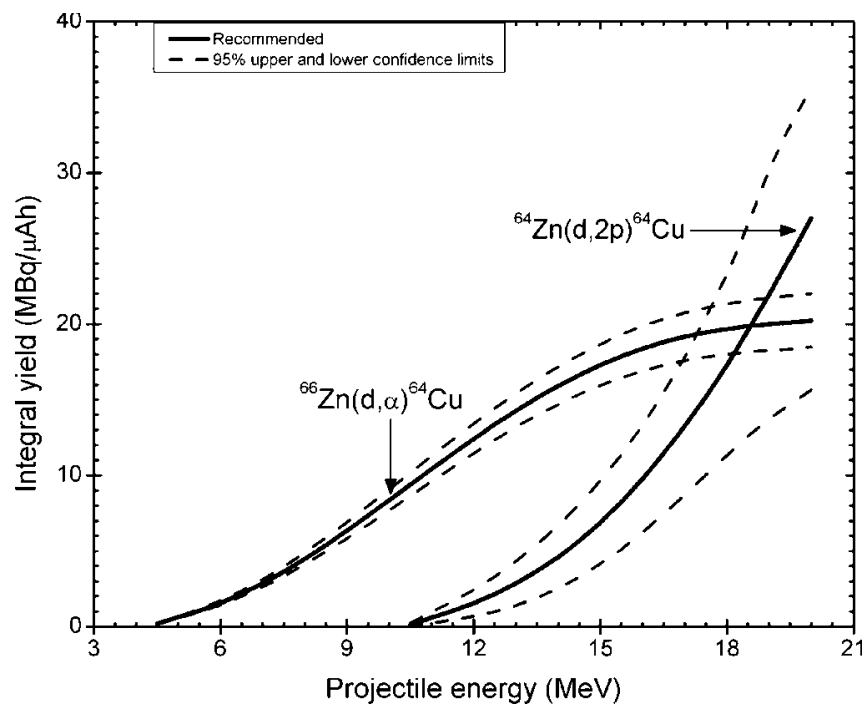

Fig. 22. Calculated integral yields for the ${ }^{64} \mathrm{Zn}(d, 2 p)^{64} \mathrm{Cu}$ and ${ }^{66} \mathrm{Zn}(d, \alpha){ }^{64} \mathrm{Cu}$ reactions.

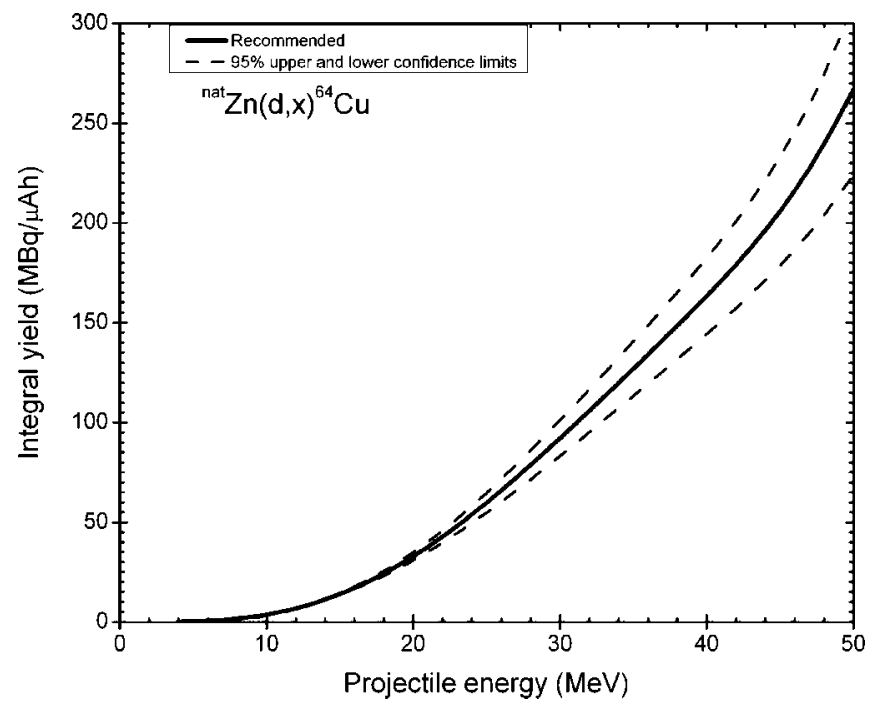

Fig. 23. Calculated integral yield for the ${ }^{\text {nat }} \mathrm{Zn}(d, x)^{64} \mathrm{Cu}$ reaction. 
example [85]) The significance of the calculated yield is to define the ideal (maximum) value which can be obtained via a given reaction.

\section{Comparison of evaluated data}

Out of the seven nuclear reactions evaluated in this work, four processes, namely ${ }^{64} \mathrm{Ni}(p, n){ }^{64} \mathrm{Cu},{ }^{64} \mathrm{Ni}(d, 2 n){ }^{64} \mathrm{Cu}$, ${ }^{68} \mathrm{Zn}(p, \alpha n){ }^{64} \mathrm{Cu}$ and ${ }^{\text {nat }} \mathrm{Zn}(d, x){ }^{64} \mathrm{Cu}$, are the same as previously evaluated under an IAEA-CRP [16]. For the ${ }^{64} \mathrm{Ni}(p, n){ }^{64} \mathrm{Cu}$ and ${ }^{\text {nat }} \mathrm{Zn}(d, x){ }^{64} \mathrm{Cu}$ reactions, the cross sections and integral yields recommended by the CRP are higher than our recommended values by $5-20 \%$ and $6-15 \%$, respectively. In the case of the other two reactions, however, the CRP data are only 2-10\% higher than our recommended data. Part of the difference arises possibly from the normalization of experimental cross section data to the new decay data of ${ }^{64} \mathrm{Cu}$. This was done in the present work but not under the CRP.

\section{Comparison of production routes of ${ }^{64} \mathrm{Cu}$}

The cyclotron production of a medical radionuclide demands consideration of cross section data not only of the desired reaction (to calculate the integral yield) but also of other competing reactions leading to possible disturbing radioactive impurities. In irradiations of zinc isotopes with protons and deuterons, besides radiocopper, appreciable amounts of gallium radioisotopes are formed. They can, however, be chemically separated from radiocopper. Similarly in irradiations of nickel isotopes, several radioisotopes of nickel, cobalt and iron may be formed which can also be chemically removed. The major concern regarding the radionuclidic purity of ${ }^{64} \mathrm{Cu}$ is thus related to the presence of ${ }^{61} \mathrm{Cu}\left(T_{1 / 2}=3.4 \mathrm{~h}\right)$ and ${ }^{67} \mathrm{Cu}\left(T_{1 / 2}=61.9 \mathrm{~h}\right)$. Using highly enriched target material and through proper choice of the projectile energy range in the target it is possible to obtain high-purity ${ }^{64} \mathrm{Cu}$. We give in Table 9 a comparison of the various nuclear processes evaluated in this work with regard to the production of ${ }^{64} \mathrm{Cu}$. In each case the optimum energy range and the thick target yield are given.

Of all the investigated processes, the ${ }^{64} \mathrm{Ni}(p, n){ }^{64} \mathrm{Cu}$ reaction has been technically developed (see introduction)

Table 9. Comparison of production routes of ${ }^{64} \mathrm{Cu}$.

\begin{tabular}{lcc}
\hline Nuclear process & $\begin{array}{c}\text { Optimum energy } \\
\text { range }(\mathrm{MeV})\end{array}$ & $\begin{array}{c}\text { Thick target yield } \\
(\mathrm{MBq} / \mu \mathrm{A} h)\end{array}$ \\
\hline${ }^{64} \mathrm{Ni}(p, n)^{64} \mathrm{Cu}^{a}$ & $12 \rightarrow 8$ & 304 \\
${ }^{64} \mathrm{Ni}(d, 2 n)^{64} \mathrm{Cu}^{a}$ & $17 \rightarrow 11$ & 430 \\
${ }^{68} \mathrm{Zn}(p, \alpha n)^{64} \mathrm{Cu}^{a}$ & $30 \rightarrow 21^{b}$ & 116 \\
${ }^{66} \mathrm{Zn}(p, 2 p n)^{64} \mathrm{Cu}^{a}$ & $52 \rightarrow 37$ & 316 \\
${ }^{64} \mathrm{Zn}(d, 2 p)^{64} \mathrm{Cu}^{a}$ & $20 \rightarrow 10$ & 27.1 \\
${ }^{66} \mathrm{Zn}(d, \alpha)^{64} \mathrm{Cu}^{a}$ & $13 \rightarrow 5$ & 13.8 \\
${ }^{\mathrm{nat}} \mathrm{Zn}(d, x)^{64} \mathrm{Cu}$ & $25 \rightarrow 10^{c}$ & 57.0 \\
\hline
\end{tabular}

a: Using highly enriched target material, low enrichment will lead to impurities;

b: Below threshold of ${ }^{67} \mathrm{Cu}$ impurity via the ${ }^{68} \mathrm{Zn}(p, 2 p){ }^{67} \mathrm{Cu}$ reaction;

c: Below thresholds of ${ }^{61} \mathrm{Cu}$ and ${ }^{67} \mathrm{Cu}$ impurities via the ${ }^{64} \mathrm{Zn}(d, \alpha n){ }^{61} \mathrm{Cu}$ and ${ }^{68} \mathrm{Zn}(d, 2 p n)^{67} \mathrm{Cu}$ reactions, respectively. and is now being commercialized. This is mainly because a low-energy proton cyclotron $\left(E_{\mathrm{p}} \leq 18 \mathrm{MeV}\right)$ delivering beam currents of $50-100 \mu \mathrm{A}$ is adequate for production purposes. Since the present day commercial cyclotrons have deuteron energies only half of the proton energies and since the available deuteron beam currents are low $(<30 \mu \mathrm{A})$, the ${ }^{64} \mathrm{Ni}(d, 2 n){ }^{64} \mathrm{Cu}$ reaction has hitherto not been used for large scale production of ${ }^{64} \mathrm{Cu}$. The main advantage of the ${ }^{68} \mathrm{Zn}(p, \alpha n){ }^{64} \mathrm{Cu}$ reaction is that ${ }^{64} \mathrm{Cu}$ is obtained as a byproduct in ${ }^{67} \mathrm{Ga}$ production, although appreciable chemical processing effort is involved. The ${ }^{\text {nat }} \mathrm{Zn}(d, x)^{64} \mathrm{Cu}$ process entails the advantage of using ${ }^{\text {nat }} \mathrm{Zn}$ as target material, although a stringent control of the energy range in the target is essential.

\section{Conclusion}

All the significant charged particle induced reactions for the production of ${ }^{64} \mathrm{Cu}$ were evaluated. The experimental cross sections for each reaction were compared with nuclear model calculations. Good agreement could be achieved between calculated and measured excitation functions by a careful choice of nuclear model parameters. Of particular importance was the choice of optical model parameters (OMPs), nuclear structure and level densities. In general, the model calculations did not validate the absolute values of experimental data, but were able to validate the consistency of different experiments in different energy ranges. Good experiments indirectly help to refine nuclear models, particularly in depicting the significance of various model parameters. Thus experiment and nuclear modeling have a synergistic relationship. The recommended sets of data should be useful for optimizing various routes for the production of ${ }^{64} \mathrm{Cu}$ at accelerators or cyclotrons. The ${ }^{64} \mathrm{Ni}(p, n){ }^{64} \mathrm{Cu}$ reaction is the method of choice for production of large quantities of high-purity ${ }^{64} \mathrm{Cu}$.

Acknowledgment. Two of the authors, M. N. Aslam and M. Hussain, are grateful to the Higher Education Commission (HEC) of Pakistan for financing the visit to Debrecen University under the International Research Support Initiative Program (IRSIP). They thank the University of Debrecen for facilitating research and would also like to acknowledge the IAEA for providing an opportunity to participate in the workshop on the code EMPIRE, held in Vienna in December 2008.

\section{References}

1. Stöcklin, G., Qaim, S. M., Rösch, F.: The impact of radioactivity on medicine. Radiochim. Acta 70/71, 249-272 (1995).

2. Qaim, S. M.: Nuclear data for production of new medical radionuclides. J. Nucl. Sci. Technol. Suppl. 2, 1272-1277 (2002).

3. Qaim, S. M.: Cyclotron production of medical radionuclides. In: Handbook of Nuclear Chemistry. (Vertes, A., Nagy, S., Klencsár, Z., eds.) Kluwer, Dordrecht, The Netherlands (2003), Vol. 4, pp. 47-79.

4. Laforest, R., Liu, X.: Image quality with non-standard nuclides in PET. Q. J. Nucl. Med. Mol. Imaging 52, 151-158 (2008).

5. Herzog, H., Tellmann, L., Scholten, B., Coenen, H. H., Qaim, S. M.: PET imaging problems with the non-standard positron emitters yttrium-86 and iodine-124. Q. J. Nucl. Med. Mol. Imaging 52, 159-165 (2008).

6. Blower, P. J., Lewis, J. S., Zweit, J.: Copper radionuclides and radiopharmaceuticals in nuclear medicine. Nucl. Med. Biol. 23, 957-980 (1996). 
7. Anderson, C. J., Connett, J. M., Schwarz, S. W., Rocque, P. A., Guo, L. W., Philpott, G. W., Zinn, K. R., Meares, C. F., Welch, M. J.: Copper-64 labeled antibodies for PET imaging. J. Nucl. Med. 33, 1685-1691 (1992).

8. Philpott, G. W., Schwarz, S. W., Anderson, C. J., Dehdashti, F., Connett, J. M., Zinn, K. R., Meares, C. F., Cutler, P. D., Welch, M. J., Siegel, B. A.: Radio-immunoPET: Detection of colorectal carcinoma with positron-emitting copper-64 labeled monoclonal antibody. J. Nucl. Med. 36, 1818-1824 (1995).

9. Smith, S. V., Di Bartolo, N., Sargeson, A., Hetherington, E.: Amino-benzyl-cryptate - A new ligand for radiolabelling with ${ }^{64} \mathrm{Cu}$, its potential for diagnostic and therapeutic applications. J. Labelled Compd. Radiopharm. 42 (Suppl. 1), 841-843 (1999).

10. Sun, X., Anderson, C. J.: Production and applications of copper64 radiopharmaceuticals. Methods Enzymol. 386, 237-261 (2004).

11. Al-Abyad, M., Spahn, I., Sudár, S., Morsy, M., Comsan, M. N. H., Csikai, J., Qaim, S. M., Coenen, H. H.: Nuclear data for production of the therapeutic radionuclides ${ }^{32} \mathrm{P},{ }^{64} \mathrm{Cu},{ }^{67} \mathrm{Cu},{ }^{89} \mathrm{Sr},{ }^{90} \mathrm{Y}$ and ${ }^{153} \mathrm{Sm}$ via the $(n, p)$ reaction: Evaluation of excitation function and its validation via integral cross section measurement using a $14 \mathrm{MeV}$ d(Be) neutron source. Appl. Radiat. Isot. 64, 717-724 (2006).

12. Szelecsényi, F., Blessing, G., Qaim, S. M.: Excitation functions of proton induced nuclear reactions on enriched ${ }^{61} \mathrm{Ni}$ and ${ }^{64} \mathrm{Ni}$ : Possibility of production of no-carrier-added ${ }^{61} \mathrm{Cu}$ and ${ }^{64} \mathrm{Cu}$ at a small cyclotron. Appl. Radiat. Isot. 44, 575-580 (1993).

13. McCarthy, D. W., Shefer, R. E., Klinkowstein, R. E., Bass, L. A., Margeneau, W. H., Cutler, C. S., Anderson, C. J., Welch, M. J.: Efficient production of high specific activity ${ }^{64} \mathrm{Cu}$ using a biomedical cyclotron. Nucl. Med. Biol. 24, 35-43 (1997).

14. Szajek, L. P., Meyer, W., Plascjak, P., Eckelman, W. C.: Semiremote production of $\left[{ }^{64} \mathrm{Cu}\right] \mathrm{CuCl}_{2}$ and preparation of high specific activity $\left[{ }^{64} \mathrm{Cu}\right] \mathrm{Cu}$-ATSM for PET studies. Radiochim. Acta 93, 239-244 (2005)

15. Qaim, S. M.: Decay data and production yields of some nonstandard positron emitters used in PET. Q. J. Nucl. Med. Mol. Imaging 52, 111-120 (2008).

16. Capote, R., Beták, E., Carlson, B. V., Choi, H. D., Ignatyuk, A., Menapace, E., Nortier, F. M., Qaim, S. M. (Chairman), Scholten, B., Shubin, Y. N., Sublet, J. C., Tárkányi, F. T.: IAEA coordinated research programme: Nuclear data for the production of therapeutic radionuclides. (Bersillon, O., Gunsing, F., Bauge, E., Jacqmin, R., Leray, S., eds.) In: Proc. Int. Conf. Nucl. Data for Science and Technology, April 22-27, 2007, Nice, France (2008), pp. 1367-1370. See also, Therapeutical radioisotopes production, http://www-nds.iaea.org/medportal/.

17. Blaser, J. P., Boehm, F., Marmier, P., Scherrer, P.: Anregungsfunktionen und Wirkungsquerschnitte der $(p, n)$-Reaktion (II). Helvet. Phys. Acta 24, 441-464 (1951).

18. Blosser, H. G., Handley, T. H.: Survey of $(p, n)$ reactions at $12 \mathrm{MeV}$. Phys. Rev. 100, 1340-1344 (1955).

19. Tanaka, S., Furukawa, M.: Excitation functions for $(p, n)$ reactions with titanium, vanadium, chromium, iron and nickel up to $E_{\mathrm{p}}=14 \mathrm{MeV}$. J. Phys. Soc. Japan 14, 1269-1275 (1959).

20. Tanaka, S., Furukawa, M., Chiba, M.: Nuclear reactions of nickel with protons upto $56 \mathrm{MeV}$. J. Inorg. Nucl. Chem. 34, 2419-2426 (1972).

21. Treytl, W. J., Caretto Jr., A. A.: Study of $(p, n)$ reactions between 100 and $400 \mathrm{MeV}$. Phys. Rev. 146, 836-840 (1966).

22. Guzhovskij, B. Ya., Borkin, I. M., Zvenigorodskij, A. G., Rudnev, V. S., Solodovnikov, A. P., Trusillo, S. V.: Isospin mixing of isobaric analog resonances observed for ${ }^{59} \mathrm{Cu},{ }^{61} \mathrm{Cu},{ }^{63} \mathrm{Cu}$ and ${ }^{65} \mathrm{Cu}$. Bull. Acad. Sci. USSR Phys. Ser. 33, 119-131 (1969).

23. Nemashkalo, B. A., Mel'Nik, Yu. P., Storizhko, V. E., Shebeko, K. V.: Radiative capture of protons by nuclei ${ }^{54} \mathrm{Cr}$ and ${ }^{64} \mathrm{Ni}$ near the threshold of the $(p, n)$ reaction. Yad. Fiz. 37, 3-13 (1983).

24. Sevior, M. E., Mitchell, L. W., Anderson, M. R., Tingwell, C. W., Sargood, D. G.: Absolute cross sections of proton induced reactions on ${ }^{65} \mathrm{Cu},{ }^{64} \mathrm{Ni}$ and ${ }^{63} \mathrm{Cu}$. Austral. J. Phys. 36, 463-471 (1983).

25. Levkovskij, V. N.: Activation cross sections of nuclides of average masses $(A=40-100)$ by protons and alpha particles with average energies $(E=10-50 \mathrm{MeV})$. Inter-Vesi, Moscow, USSR (1991).
26. Antropov, A. E., Gusev, V. P., Zhuravlev, Yu. Yu., Zarubin, P. P., Kolozhvary, A. A., Smirnov, A. V.: Total cross sections of the $(p, n)$ reaction at nickel and zinc isotopes nuclei at $E_{\mathrm{p}}=5-6 \mathrm{MeV}$. Bull. Acad. Sci. USSR Phys. Ser. 56, 1829-1835 (1992).

27. Avila-Rodriguez, M. A., Nye, J. A., Nickles, R. J.: Simultaneous production of high specific activity ${ }^{64} \mathrm{Cu}$ and ${ }^{61} \mathrm{Co}$ with $11.4 \mathrm{MeV}$ protons on enriched ${ }^{64} \mathrm{Ni}$ nuclei. Appl. Radiat. Isot. 65, 11151120 (2007).

28. Rebeles, R. A., Van den Winkel, P., Hermanne, A, Tárkányi, F.: New measurement and evaluation of the excitation function of ${ }^{64} \mathrm{Ni}(p, n)$ reaction for the production of ${ }^{64} \mathrm{Cu}$. Nucl. Instrum. Methods B 267, 457-461 (2009).

29. Zweit, J., Smith, A. M., Downey, S., Sharma, H. L.: Excitation functions for deuteron induced reactions in natural nickel: Production of no-carrier-added ${ }^{64} \mathrm{Cu}$ from enriched ${ }^{64} \mathrm{Ni}$ targets for positron emission tomography. Appl. Radiat. Isot. 42, 193-197 (1991).

30. Takács, S., Tárkányi, F., Király, B., Hermanne, A., Sonck, M.: Evaluated activation cross sections of longer-lived radionuclides produced by deuteron induced reactions on natural nickel. Nucl. Instrum. Methods B 260, 495-507 (2007).

31. Hermanne, A., Tárkányi, F., Takács, S., Kovalev, S. F., Ignatyuk, A.: Activation cross sections of the ${ }^{64} \mathrm{Ni}(d, 2 n)$ reaction for the production of the medical radionuclide ${ }^{64} \mathrm{Cu}$. Nucl. Instrum. Methods B 258, 308-312 (2007).

32. Daraban, L., Rebeles, R. A., Hermanne, A.: Study of the excitation function for the deuteron induced reaction on ${ }^{64} \mathrm{Ni}(d, 2 n)$ for the production of the medical radioisotope ${ }^{64} \mathrm{Cu}$. Appl. Radiat. Isot. 67, 506-510 (2009).

33. Hilgers, K., Stoll, T., Skakun, Y., Coenen, H. H., Qaim, S. M.: Cross section measurements of the nuclear reactions ${ }^{\text {nat }} \mathrm{Zn}(d, x)$ ${ }^{64} \mathrm{Cu},{ }^{66} \mathrm{Zn}(d, \alpha){ }^{64} \mathrm{Cu}$ and ${ }^{68} \mathrm{Zn}(p, \alpha n){ }^{64} \mathrm{Cu}$ for production of ${ }^{64} \mathrm{Cu}$ and technical developments for small-scale production of ${ }^{67} \mathrm{Cu}$ via the ${ }^{70} \mathrm{Zn}(p, \alpha){ }^{67} \mathrm{Cu}$ process. Appl. Radiat. Isot. 59, 343-351 (2003).

34. Hilgers, K., Qaim, S. M., Coenen, H. H.: New cross section data for production of the therapeutic radionuclides ${ }^{64} \mathrm{Cu},{ }^{140} \mathrm{Nd}$ and ${ }^{192}$ Ir. In: Proc. Int. Conf. Nucl. Data for Science and Technology, Santa Fe, NM, USA., 26 Sep-1 Oct, 2004. AIP Conf. Proc. 769, 1631-1633 (2005).

35. Szelecsényi, F., Steyn, G. F., Kovács, Z., Vermeulen, C., van der Meulen, N. P., Dolley, S. G., van der Walt, T. N., Suzuki, K., Mukai, K.: Investigation of the ${ }^{66} \mathrm{Zn}(p, 2 p n){ }^{64} \mathrm{Cu}$ and ${ }^{68} \mathrm{Zn}(p, x)$ ${ }^{64} \mathrm{Cu}$ nuclear processes upto $100 \mathrm{MeV}$ : Production of ${ }^{64} \mathrm{Cu}$. Nucl. Instrum. Methods B 240, 625-637 (2005).

36. Szelecsényi, F., Steyn, G. F., Suzuki, K., Kovács, Z., van der Walt, T. N., Vermeulen, C., van der Meulen, N. P., Dolley, S. G., Mukai, K.: Application of $\mathrm{Zn}+\mathrm{p}$ reactions for production of copper radioisotopes for medical studies. (Bersillon, O., Gunsing, F., Bauge, E., Jacqmin, R., Leray, S., eds.) In: Proc. Int. Conf. Nucl. Data for Science and Technology, April 22-27, 2007, Nice, France (2008), pp. 1395-1398.

37. Williams, D. C., Irvine, J. W.: Nuclear excitation functions and thick target yields: $\mathrm{Zn}+\mathrm{d}$ and ${ }^{40} \operatorname{Ar}(d, \alpha)$. Phys. Rev. 130, 265-271 (1963).

38. Daraban, L., Abbas, K., Simonelli, F., Rebeles, R. A., Gibson, N.: Experimental study of excitation functions for the deuteron induced reactions ${ }^{64} \mathrm{Zn}(d, 2 p){ }^{64} \mathrm{Cu}$ and ${ }^{64} \mathrm{Zn}(d, \alpha n){ }^{61} \mathrm{Cu}$ using the stacked-foil technique. Appl. Radiat. Isot. 66, 261-264 (2008).

39. Bonardi, M. L., Groppi, F., Birattari, C., Gini, L., Mainardi, C., Ghioni, A., Menapace, E., Abbas, K., Holzwarth, U., Stroosnijder, M. F.: Thin-target excitation functions and optimisation of simultaneous production of $\mathrm{NCA}{ }^{64} \mathrm{Cu}$ and ${ }^{66,67} \mathrm{Ga}$ by deuteron induced nuclear reactions on a natural zinc target. J. Radioanal. Nucl. Chem. 257, 229-241 (2003).

40. Groppi, F., Bonardi, M. L., Birattari, C., Gini, L., Mainardi, C., Menapace, E., Abbas, K., Holzwarth, U., Stroosnijder, R. M. F.: Thin target excitation functions and optimization of NCA ${ }^{64} \mathrm{Cu}$ and ${ }^{66,67} \mathrm{Ga}$ production by deuteron induced nuclear reactions on natural zinc target, for radiometabolic therapy and for PET. Nucl. Instrum. Methods B 213, 373-377 (2004).

41. Tárkányi, F., Takács, S., Ditrói, F., Hermanne, A., Sonck, M., Shubin, Yu.: Excitation functions of deuteron induced nuclear reac- 
tions on natural zinc up to $50 \mathrm{MeV}$. Nucl. Instrum. Methods B 217, 531-550 (2004).

42. Gul, K., Hermanne, A., Mustafa, M. G., Nortier, F. M., Obložinskỳ, P., Qaim, S. M., Scholten, B., Shubin, Y., Takács, S., Tárkányi, F. T., Zhuang, Y.: Charged Particle Cross Section Database for Medical Radioisotope Production, IAEA- TECDOC-1211, Vienna (2001), pp. 1-284, www-nds.iaea.org/medical.

43. Takács, S., Tárkányi, F., Sonck, M., Hermanne, A.: Investigation of the ${ }^{\text {nat }} \mathrm{Mo}(p, x)^{96 \mathrm{~m}, \mathrm{~g}} \mathrm{Tc}$ nuclear reaction to monitor proton beams: New measurements and consequences on the earlier reported data. Nucl. Instrum. Methods B 198, 183-196 (2002).

44. Qaim, S. M., Bisinger, T., Hilgers, K., Nayak, D., Coenen, H. H.: Positron emission intensities in the decay of ${ }^{64} \mathrm{Cu},{ }^{76} \mathrm{Br}$ and ${ }^{124} \mathrm{I}$. Radiochim. Acta 95, 67-73 (2007).

45. Uhl, M., Strohmaier, B.: Computer code for particle induced activation cross section and related quantities. Institut für Radiumforschung und Kernphysik, Vienna, Report 76/01, Vienna, and Addendum to this report (1976).

46. Strohmaier, B., Uhl, M.: International Atomic Energy Agency Report IAEA-SMR-43, 313 (1980).

47. Sudár, S., Qaim, S. M.: Excitation functions of proton and deuteron induced reactions on iron and $\alpha$-particle induced reactions on manganese in the energy region up to $25 \mathrm{MeV}$. Phys. Rev. C 50, 2408-2419 (1994).

48. Qaim, S. M., Sudár, S., Fessler, A.: Influence of reaction channel on the isomeric cross-section ratio. Radiochim. Acta 93, 503-506 (2005).

49. Sudár, S., Qaim, S. M.: Cross sections for the formation of ${ }^{195 \mathrm{~m}, \mathrm{~g}} \mathrm{Hg},{ }^{197 \mathrm{~m}, \mathrm{~g}} \mathrm{Hg}$ and ${ }^{196 \mathrm{~m}, \mathrm{~g}} \mathrm{Au}$ in $\alpha$ - and ${ }^{3} \mathrm{He}$-particle induced reactions on Pt: Effect of level density parameters on the calculated isomeric cross section ratio. Phys. Rev. C 73, 034613, 1-11 (2006).

50. Griffin, J. J.: Statistical model of intermediate structure. Phys. Rev. Lett. 17, $\overline{478-48} 1$ (1966).

51. Hauser, W., Feshbach, H.: The inelastic scattering of neutrons.

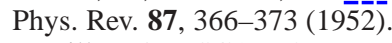

52. Bersillon, O.: SCAT 2: Un programme de modele optique spherique. Centre d'Etudes de Bruyéres-le-Châtel Report, CEAN-2227 (1981).

53. Belgya, T., Bersillon, O., Capote, R., Fukahori, T., Zhigang, G., Goriely, S., Herman, M., Ignatyuk, A. V., Kailas, S., Koning, A., Obložinsky, P., Plujko, V., Young, P.: Handbook for calculations of nuclear reaction data, Reference Input Parameter Library2. Tech. Rep. IAEA-TECDOC-1506, IAEA, Vienna, Austria (2006), pp. 1-159, http://www-nds.iaea.or.at/RIPL-2.

54. Kalbach-Cline, C.: Residual two-body matrix element for preequilibrium calculations. Nucl. Phys. A 210, 590-604 (1973).

55. Brink, D. M.: Individual particle and collective aspects of the nuclear photoeffect. Nucl. Phys. 4, 215-220 (1957).

56. Axel, P.: Electric dipole ground state transition width strength function and $7 \mathrm{MeV}$ photon interactions. Phys. Rev. 126, 671-683 (1962).

57. Dilg, W., Schantl, W., Vonach, H., Uhl, M.: Level density parameters for the back-shifted Fermi gas model in the mass range $40<A<250$. Nucl. Phys. A 217, 269-298 (1973).

58. Herman, M., Obložinský, P., Capote, R., Sin, M., Trkov, A., Ventura, A., Zerkin, V.: Recent development of the nuclear reaction model code EMPIRE. In: Proc. Int. Conf. Nucl. Data for Science and Technology, Santa Fe, USA, Sep 26-Oct 1, 2004. AIP Conf. Proc. 769, 1184-1187 (2005), http://www.nndc.bnl.gov/ empire219.

59. Raynal, J.: Notes on ECIS-94, CEA Saclay Report No. CEA-N2772 (1994).

60. Tamura, T., Udagawa, T., Lenske, H.: Multistep direct reaction analysis of continuum spectra in reactions induced by light ions. Phys. Rev. C 26, 379-404 (1982).

61. Nishioka, H., Verbaarschot, J. J. M., Weidenmüller, H. A., Yoshida, S.: Statistical theory of precompound reactions: The multistep compound process. Ann. Phys. 172, 67-99 (1986).

62. Herman, M., Hoering, A., Reffo, G.: Gamma emission in precompound reactions. II. Numerical application. Phys. Rev. C 46, 2493-2500 (1992).
63. Beták, E., Oblžinsky, P.: Code PEGAS: Pre-equilibrium exciton model with spin conservation and gamma emission. Technical Report INDC(SLK)-001, IAEA/Slovak Academy of Sciences (1993).

64. Hofmann, H. M., Richert, J., Tepel, J. W., Weidenmüller, H. A.: Direct reactions and Hauser-Feshbach theory. Ann. Phys. 90, 403 (1975).

65. Koning, A. J., Hilaire, S., Duijvestijn, M. C.: TALYS-1.0. (Bersillon, O., Gunsing, F., Bauge, E., Jacqmin, R., Leray, S., eds.) In: Proc. Int. Conf. Nucl. Data for Science and Technology, April 22-27, 2007, Nice, France, EDP Sciences (2008), pp. 211-214.

66. Koning, A. J., Delaroche, J. P.: Local and global nucleon optical models from $1 \mathrm{keV}$ to $200 \mathrm{MeV}$. Nucl. Phys. A 713, 231-310 (2003).

67. Watanabe, S.: High energy scattering of deuterons by complex nuclei. Nucl. Phys. 8, 484-492 (1958).

68. Moldauer, P. A.: Statistics and the average cross section. Nucl. Phys. A 344, 185-195 (1980).

69. Koning, A. J., Duijvestijn, M. C.: A global pre-equilibrium analysis from 7 to $200 \mathrm{MeV}$ based on the optical model potential, Nucl. Phys. A 744, 15-76 (2004).

70. Kalbach, C.: Pre-equilibrium reactions with complex particle channels. Phys. Rev. C 71, 034606 (2005).

71. Wilmore, D., Hodgson, P. E.: The calculation of neutron crosssections from optical potentials. Nucl. Phys. 55, 673-694 (1964)

72. McFadden, L., Satchler, G. R.: Optical model analysis of the scattering of 24.7 MeV $\alpha$-particles. Nucl. Phys. 84, 177-200 (1966).

73. Bojowald, J., Machner, H., Nann, H., Oelert, W., Rogge, M., Turek, P.: Elastic deuteron scattering and optical model parameters at energies up to $100 \mathrm{MeV}$. Phys. Rev. C 38, 1153-1163 (1988).

74. Stoll, T., Kastleiner, S., Shubin, Y. N. Coenen, H. H., Qaim, S. M.: Excitation functions of proton induced reactions on ${ }^{68} \mathrm{Zn}$ from threshold up to $71 \mathrm{MeV}$, with specific reference to the production of ${ }^{67} \mathrm{Cu}$. Radiochim. Acta 90, 309-313 (2002).

75. Becchetti Jr., F. D., Greenlees, G. W.: Nucleon-nucleus optical model parameters, $A>40, E<50 \mathrm{MeV}$. Phys. Rev. 182, 11901209 (1969).

76. Lohr, J. M., Haeberli, W.: Elastic scattering of $9-13 \mathrm{MeV}$ vector polarized deuteron. Nucl. Phys. A 232, 381-397 (1974).

77. Neirincks, R. D.: Simultaneous production of ${ }^{67} \mathrm{Cu},{ }^{64} \mathrm{Cu}$ and ${ }^{67} \mathrm{Ga}$ and labelling of bleomycin with ${ }^{67} \mathrm{Cu}$ or ${ }^{64} \mathrm{Cu}$. Appl. Radiat. Isot. 28, 802-804 (1977).

78. Nickles, R. J.: A shotgun approach to the chart of the nuclides, Radiotracer production with an $11 \mathrm{MeV}$ proton cyclotron. Acta Radiol. Suppl. 376, 69-71 (1991).

79. Obata, A., Kasamatsu, S., McCarthy, D. W., Welch, M. J., Saji, H., Yonekura, Y., Fujibayashi, Y.: Production of therapeutic quantities of ${ }^{64} \mathrm{Cu}$ using a $12 \mathrm{MeV}$ cyclotron. Nucl. Med. Biol. 30, 535-539 (2003).

80. Abbas, K., Kozempel, J., Bonardi, M., Groppi, F., Alfarano, A., Holzwarth, U., Simonelli, F., Hofman, H., Horstmann, W., Menapace, E., Lešetický, L., Gibson, N.: Cyclotron production of ${ }^{64} \mathrm{Cu}$ by deuteron irradiation of ${ }^{64} \mathrm{Zn}$. Appl. Radiat. Isot. 64, 1001-1005 (2006).

81. Kozempel, J., Abbas, K., Simonelli, F., Zampese, M., Holzwarth, U., Gibson, N., Lešetický, L.: A novel method for n.c.a. ${ }^{64} \mathrm{Cu}$ production by the ${ }^{64} \mathrm{Zn}(d, 2 p){ }^{64} \mathrm{Cu}$ reaction and dual ion-exchange column chromatography. Radiochim. Acta 95, 75-80 (2007).

82. Abbas, K., Birattari, C., Bonardi, M., Groppi, F., Menapace, E., Shaw, D., Severgnini, M., Stroosnijder, M. F.: Cyclotron production of $\mathrm{NCA}^{64} \mathrm{Cu}$ from deuteron irradiation of zinc target. J. Labelled Compd. Radiopharm. 44 (Suppl. 1), S802-S805 (2001).

83. Boothe, T. E., Tavano, E., Munoz, J., Carroll, S.: Coproduction of ${ }^{64} \mathrm{Cu}$ and ${ }^{67} \mathrm{Cu}$ with ${ }^{67} \mathrm{Ga}$ using protons on ${ }^{68} \mathrm{Zn}$. J. Labelled Compd. Radiopharm. 30, 108 (1991).

84. Smith, S. V., Waters, D. J., Di Bartolo, N.: Separation of ${ }^{64} \mathrm{Cu}$ from ${ }^{67} \mathrm{Ga}$ waste using anion-exchange and low acid aqueous/organic mixtures. Radiochim. Acta 75, 65-68 (1996).

85. Qaim, S. M.: Target development for medical radioisotope production at a cyclotron. Nucl. Instrum. Methods A 282, 289-295 (1989). 